\title{
Metabolite profile changes in xylem sap and leaf extracts of strategy I plants in response to iron deficiency and resupply
}

\author{
Rubén Rellán-Álvarez ${ }^{1}$, Hamdi El-Jendoubi ${ }^{1}$, Gert Wohlgemuth ${ }^{2}$, Anunciación Abadía ${ }^{1}$, Oliver Fiehn ${ }^{2}$, \\ Javier Abadía ${ }^{1 *}$ and Ana Álvarez-Fernández ${ }^{1}$ \\ Group of Plant Stress Physiology, Department of Plant Nutrition, Aula Dei Experimental Station, Zaragoza, Spain \\ ${ }^{2}$ Metabolomics Fiehn Lab, Genome Center, University of California Davis, CA, USA
}

\section{Edited by:}

Jan Kofod Schjoerring, University of

Copenhagen, Denmark

\section{Reviewed by:}

Graziano Zocchi, Università Degli

Studi di Milano, Italy

Toshihiro Yoshihara, Central Research

Institute of Electric Power Industry,

Japan

\section{*Correspondence:}

Javier Abadía, Group of Plant Stress

Physiology, Department of Plant

Nutrition, Aula Dei Experimental

Station, P.O. Box 13034, Zaragoza

E-50080, Spain

e-mail: jabadia@eead.csic.es
The metabolite profile changes induced by Fe deficiency in leaves and xylem sap of several Strategy I plant species have been characterized. We have confirmed that Fe deficiency causes consistent changes both in the xylem sap and leaf metabolite profiles. The main changes in the xylem sap metabolite profile in response to Fe deficiency include consistent decreases in amino acids, $\mathrm{N}$-related metabolites and carbohydrates, and increases in TCA cycle metabolites. In tomato, Fe resupply causes a transitory flush of xylem sap carboxylates, but within 1 day the metabolite profile of the xylem sap from Fe-deficient plants becomes similar to that of Fe-sufficient controls. The main changes in the metabolite profile of leaf extracts in response to Fe deficiency include consistent increases in amino acids and N-related metabolites, carbohydrates and TCA cycle metabolites. In leaves, selected pairs of amino acids and TCA cycle metabolites show high correlations, with the sign depending of the Fe status. These data suggest that in low photosynthesis, C-starved Fedeficient plants anaplerotic reactions involving amino acids can be crucial for short-term survival.

Keywords: anaplerotic reactions, chlorosis, iron deficiency, leaves, metabolomics, xylem sap

\section{INTRODUCTION}

Iron is an essential micronutrient in plants, involved in processes such as photosynthesis, respiration, and others (Marschner, 1995). In calcareous and alkaline soils, Fe is mainly found as poorly soluble oxides and/or hydroxides, and therefore the amount of Fe available to plants is very low. Since $30 \%$ of cultivated plants are grown in calcareous soils, Fe deficiency is often a major constraint for crop productivity (Hansen et al., 2006; Rombolà and Tagliavini, 2006).

Upon sensing Fe shortage, plants develop different mechanisms that promote Fe mobilization and uptake from the rhizosphere. Plants use two distinct strategies: most species, with the exception of grasses, use a reduction-based strategy, whereas grasses use a chelation-based strategy (Strategies I and II, respectively; see recent review by Abadía et al., 2011). Strategy I is based on the reduction of rhizospheric Fe by an Fe reductase enzyme (FRO; Robinson et al., 1999), and the subsequent uptake by root cells through an $\mathrm{Fe}$ (II) transporter (IRT; Eide et al., 1996). Iron solubilization in the rhizosphere is enhanced by an $\mathrm{H}^{+}$-ATPase that is up-regulated with Fe deficiency (Santi and Schmidt, 2009). Strategy II relies on the synthesis and excretion of phytosiderophores (PS) to the rhizosphere, and the resulting Fe(III)-PS complexes are then taken up by plasma membrane YSL-type transporters (Curie et al., 2009).

Plant adaptation to Fe deficiency also involves different metabolic changes occurring at the root, xylem, leaf, and fruit level. In roots, increases in the activities of phosphoenolpyruvate carboxylase (PEPC; Andaluz et al., 2002) and several enzymes of the glycolytic pathway and the tricarboxylic acid (TCA) cycle (Herbik et al., 1996; Brumbarova et al., 2008; Li et al., 2008) have been found. The anaplerotic $\mathrm{C}$ fixation mediated by PEPC leads to an accumulation of organic acids (Abadía et al., 2002), which may play important roles in the transport of Fe and $\mathrm{C}$ via xylem to the leaf (López-Millán et al., 2000b). Organic acid concentrations in xylem sap and leaf apoplastic fluid increased markedly with Fe deficiency in several Strategy I plant species (López-Millán et al., 2000b, 2001b, 2009; Larbi et al., 2003; Jiménez et al., 2007). An increase in tricarboxylic organic acids seems to be a general response to Fe deficiency, since they have also been reported in other organisms such as Chlamydomonas reinhardtii (Bölling and Fiehn, 2006) and Saccharomyces cerevisiae (Shakoury-Elizeh et al., 2010). At the leaf level, the most characteristic Fe deficiency symptom is the yellow color of young leaves, caused by a decrease in chlorophyll and a relative enrichment in carotenoids (Abadía, 1992), associated to changes in the light-harvesting pigment-protein complex composition (Larbi et al., 2004; Timperio et al., 2007; Laganowsky et al., 2009). Iron deficiency-induced leaf chlorosis leads to reduced photosynthetic efficiency and electron transport, with less $\mathrm{C}$ being fixed via photosynthesis (Abadía, 1992; Larbi et al., 2006). In fruits, Fe deficiency leads to changes in maturity and chemical composition, depending on the availability of C (Álvarez-Fernández et al., 2011).

Iron resupply to Fe-deficient plants cause major changes in plant metabolism. These changes have been mainly studied at 
resupply times of 1 day or longer, with little information available on changes occurring in the first hours after resupply. Whereas Fe resupply leads to rapid (within 3-6 h) increases in the concentration of Fe in the xylem sap (Orera et al., 2010; Rellán-Álvarez et al., 2010a), significant increases in leaf chlorophyll concentrations and photosynthetic rates only occur after 1 or 2 days in controlled environments or 1 week in the field (Larbi et al., 2003, 2004; Timperio et al., 2007). Iron resupply ( via foliage or roots), leads to the rapid (within $24 \mathrm{~h}$ ) de-activation of transcripts associated to root Fe acquisition mechanisms, including FRO and IRT (Enomoto et al., 2007), whereas the activities of FRO and PEPC decrease at a slower pace (López-Millán et al., 2001c; Abadía et al., 2011). Xylem sap and leaf apoplastic fluid carboxylate concentrations decrease progressively with time after Fe resupply to Fe-deficient sugar beet plants (Larbi et al., 2010). In roots, organic acid concentrations and metabolite profiles reach control levels within a few days after Fe resupply (Rellán-Álvarez et al., 2010a; Abadía et al., 2011). Also, Fe resupply leads to progressive decreases in the organic acid concentrations in the whole plant (López-Millán et al., 2001a,c).

The aim of this study was to test the hypothesis that Fe deficiency may cause consistent changes in the xylem sap and leaf metabolite profiles in Strategy I plant species. Omic technologies have been recently applied in Fe deficiency studies, focusing mainly on whole plants, whole roots, and isolated thylakoid membranes: these include transcriptomic (Thimm et al., 2001; Buhtz et al., 2010; Forner-Giner et al., 2010; Yang et al., 2010; Schuler et al., 2011), proteomic (Herbik et al., 1996; Andaluz et al., 2006; Timperio et al., 2007; Brumbarova et al., 2008; Li et al., 2008; Laganowsky et al., 2009; Donnini et al., 2010; Li and Schmidt, 2010; Rellán-Álvarez et al., 2010a; Gollhofer et al., 2011; Lan et al., 2011; Rodríguez-Celma et al., 2011), and metabolomic studies (RellánÁlvarez et al., 2010a). In the present study, metabolite profiles from xylem sap and leaf extracts of tomato, lupine, peach, and sugar beet plants grown in Fe-sufficient and Fe-deficient conditions were obtained using gas chromatography-mass spectrometry (GCMS). Relevant changes were assessed using metabolite response ratios, and multivariate analysis was used to study metabolite associations. The consistency of the results obtained in the different plant species was assessed. Also, the short-term (at $6,12,18$, and $24 \mathrm{~h}$ ) effects of Fe resupply on the metabolite profiles of xylem sap from Fe-deficient tomato plants were studied.

\section{MATERIALS AND METHODS PLANT MATERIAL}

Xylem sap and leaf extracts were obtained from four different Strategy I plant species grown in controlled or field conditions. Tomato (Solanum lycopersicum L. cv. "Tres Cantos"), lupine (Lupinus albus cv. "Multolupa"), and sugar beet (Beta vulgaris L. "Monohill") plants were grown in a controlled environment chamber with a photosynthetic photon flux density at leaf height of $350 \mathrm{mmol} \mathrm{m}^{2} \mathrm{~s}^{-1}$ photosynthetic active radiation and a $16 \mathrm{~h}-22^{\circ} \mathrm{C} / 8 \mathrm{~h}-19^{\circ} \mathrm{C}$, day/night regime. Seeds were germinated and grown in vermiculite for 2 weeks. Seedlings were grown for two more weeks in half-strength Hoagland nutrient solution with $45 \mu \mathrm{M}$ Fe-EDTA [Fe(III)-ethylenediaminetetraacetate].
Then, seedlings were transferred to plastic buckets containing halfstrength Hoagland nutrient solution with either $0(-\mathrm{Fe})$ or $45 \mu \mathrm{M}$ $\mathrm{Fe}(\mathrm{III})$-EDTA (+Fe, Fe-sufficient control plants). The $\mathrm{pH}$ of the Fe-free nutrient solutions was buffered at approximately 7.7 by adding $1 \mathrm{mM} \mathrm{NaOH}$ and $1 \mathrm{gL}^{-1}$ of $\mathrm{CaCO}_{3}$, a treatment that simulates conditions usually found in the soils associated with Fe deficiency (Susín et al., 1996). Nutrient solution buffering at high $\mathrm{pH}$ is necessary, especially for sugar beet plants, to avoid Feremobilization from previously stored Fe pools in the root apoplast and subsequent leaf re-greening. After growth for 14 days in these conditions, plants grown in the zero Fe treatment showed Fe deficiency symptoms (Figure 1). Xylem sap (in tomato and lupine) and young, fully developed leaves (in tomato and sugar beet) were sampled $4 \mathrm{~h}$ after light onset, using six to eight plants per treatment as individual replications. Average leaf chlorophyll decreases in $\mathrm{Fe}$ deficient plants when compared to the Fe-sufficient controls were approximately 75,60 , and $50 \%$ in sugar beet, tomato, and lupin respectively. Also, a set of Fe-deficient tomato plants were resupplied with $\mathrm{Fe}, 4 \mathrm{~h}$ after light onset, using fresh nutrient solution containing $45 \mu \mathrm{M} F($ III)-EDTA. In tomato, xylem sap samples were taken from Fe-deficient, Fe-sufficient, and Fe-deficient, Feresupplied plants at $6,12,18$, and $24 \mathrm{~h}$ after Fe resupply, using at each sampling time six to eight plants per treatment as individual replications. Leaves were washed with analytical-grade Type I (Milli-Q Synthesis, Millipore, Bedford, MA, USA) water, and then leaf disks were cut using a $0.50-\mathrm{cm}^{2}$ cork borer, immediately frozen in liquid $\mathrm{N}_{2}$, and stored at $-80^{\circ} \mathrm{C}$ until metabolite extraction.

Fourteen-year-old peach trees [Prunus persica (L.) Batsch, cv. "Catherina" grafted on "GF677" rootstock] grown on a floodirrigated calcareous soil (Typical xerofluvent, clay-loamy texture, with $31 \%$ total $\mathrm{CaCO}_{3}, 10 \%$ active $\mathrm{CaCO}_{3}, 7 \mathrm{mg} \mathrm{kg}^{-1}$ DTPAextractable $\mathrm{Fe}, 2 \%$ organic matter, and $\mathrm{pH} 8.0$ in water) were used. The orchard was located in Peñaflor (Zaragoza, Spain), had a frame of $2.5 \mathrm{~m} \times 6 \mathrm{~m}$, and was appropriately maintained in terms of nutrition, pruning and pest, and disease control. Some trees did not receive any Fe fertilization for 2 years prior to the beginning of the trial. Tree Fe status was monitored by estimating leaf Chl concentration with a hand-held Chl meter (SPAD-502, Minolta Corp., Osaka, Japan) using the third and forth leaves from the shoot tip. All SPAD data shown were measured at leaf sampling time. Five trees were selected and grouped into two classes: three trees with no chlorosis symptoms in the springtime season but with a slight chlorosis at the sampling time (slight Fe deficiency, with leaf chlorophyll concentrations in the range 90-225 $\mu \mathrm{mol} \mathrm{m}^{-2}$; Figure 1D) and two trees with severe Fe deficiency symptoms (severe Fe deficiency, with leaf chlorophyll concentrations in the range $45-80 \mu \mathrm{mol} \mathrm{m}^{-2}$; Figure $\mathbf{1 H}$ ). Seven current-year branches $(25-30 \mathrm{~cm}$ in length) were taken from each tree in July 2008 between 7:00 and 8:00 AM solar time, and leaf disks were sampled from the third to forth leaf, in the field and as described above. Then, branch cuttings were protected with a wet paper towel and immediately brought to the laboratory for xylem extraction.

\section{XYLEM SAP SAMPLING}

Xylem sap was collected from tomato and lupine plants by detopping plants 3-4 cm above the cotyledons (López-Millán et al., 

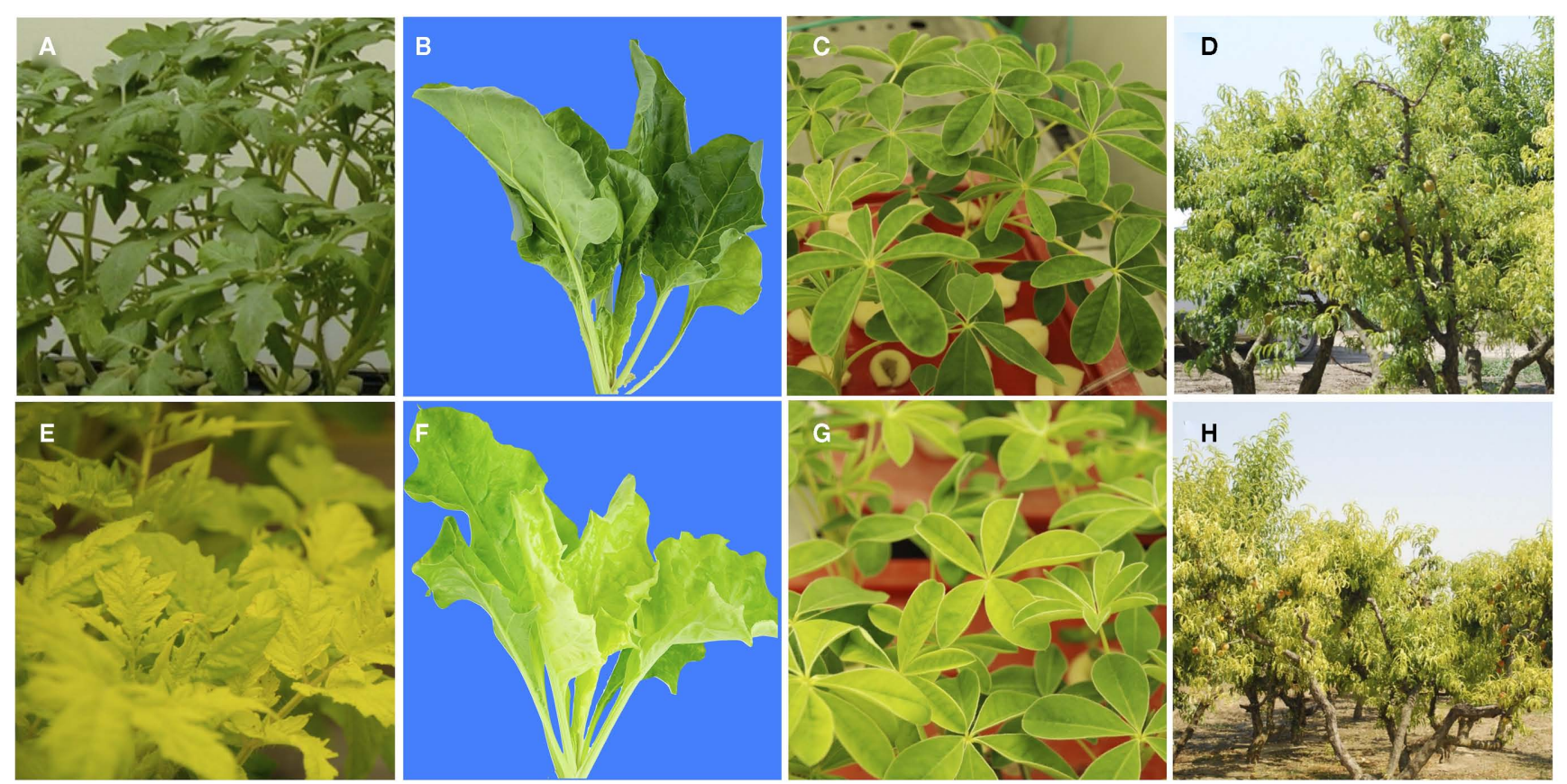

FIGURE 1 | Plant appearance at sampling time. Plants grown in Fe-sufficient conditions: (A) tomato, (B) sugar beet, (C) lupine, and (D) peach tree. Plants grown in Fe-deficient conditions: $(\mathbf{E})$ tomato, $(\mathbf{F})$ sugar beet, $(\mathbf{G})$ lupine, and $(\mathbf{H})$ peach trees.

2009). Stumps were allowed to bleed for 2-3 min, the resulting sap drops were discarded, the cut surface was wiped out with paper tissue, cleaned with distilled water, and blotted dry. Then, xylem sap was collected for $20 \mathrm{~min}$, using a micro-pipette, in Eppendorf tubes kept on ice. Extraction of peach xylem sap from branches was carried out as described elsewhere (Larbi et al., 2003) with some modifications. The branch cutting was devoid of the basal bark $(3-4 \mathrm{~cm})$, washed with distilled water, and placed in a Schölander chamber with the distal end, including leaves, inside the pressure chamber. Then, pressure was increased progressively from 5 to 22 bars; higher-pressure values resulted in cytosolic contamination (data not shown). The first few drops of sap were discarded to avoid contamination, the cut surface was wiped out with paper tissue, cleaned with Type I water, and blotted dry. Then, xylem sap was collected for $4 \mathrm{~min}$, using a micro-pipette, in Eppendorf tubes kept on ice. Cytosolic malate dehydrogenase $c$-mdh (EC 1.1.1.37) was used as xylem sap cytosolic contamination marker in all cases (López-Millán et al., 2000b).

\section{IRON DETERMINATION}

Iron in the xylem sap was determined by graphite furnace atomic absorption spectrometry (Varian SpectrAA with Zeeman correction). Samples were analyzed with six biological and three technical replications each.

\section{METABOLITE EXTRACTION AND DERIVATIZATION}

Metabolite extraction was carried out as previously described for xylem sap (Fiehn, 2003) and leaf extracts (Fiehn et al., 2008). The dried extracts were derivatized as described elsewhere (Fiehn et al., 2008).

\section{METABOLITE ANALYSIS BY GAS CHROMATOGRAPHY-MASS SPECTROMETRY AND DATA PROCESSING}

Derivatized samples $(1 \mu \mathrm{L})$ were injected randomly in split-less mode with a cold injection system (Gerstel, Mülheim an der Ruhr, Germany) and analyzed by a GC device (Agilent 6890, San Jose, CA, USA) using an integrated guard column (Restek, Bellefonte, PA, USA) and an Rtx 5Sil MS column (30 $\mathrm{m} \times 0.25 \mathrm{~mm}, 0.25 \mu \mathrm{m}$ film thickness). The GC device was connected to a Leco Pegasus IV time-of-flight mass spectrometer (TOFMS) controlled with Leco Chroma-TOF software v.2.32 (Leco, St. Joseph, MI, USA). Peak detection and mass spectra deconvolution were performed with Leco Chroma-TOF software v.2.25, and GC-MS chromatograms were processed as described previously (Fiehn et al., 2008). The optimization of the sample processing for GC-MS analysis was carried out for tomato, lupine and peach tree xylem and tomato, sugar beet, and peach leaf extracts.

\section{DATA PROCESSING AND ANALYSIS}

Metabolite data were normalized using the sum of all metabolite peak heights in a single run, to account for small GC injection variations. The resulting data were multiplied by a constant factor in order to obtain values without decimal figures. Peaks were identified using the Fiehn Lab database ${ }^{1}$. Metabolite spectra, including those of identified metabolites and unknowns, can be queried and downloaded at the Fe Chlorosis Database ${ }^{2}$. Data were analyzed to check for possible correlations between peak height values and peak variance, and since a positive correlation was found a $\log _{10}$

\footnotetext{
${ }^{1}$ http://fiehnlab.ucdavis.edu/Metabolite-Library-2007/

${ }^{2}$ http://uranus.fiehnlab.ucdavis.edu:8080/fechlodb/
} 
transformation of the data was carried out to avoid variance-mean dependence (Chich et al., 2007).

Statistical analysis of the normalized $\log _{10}$ transformed data was carried out with Statistica software (v.9.0. StatSoft, Inc., Tulsa, OK, USA). In each plant species and tissue, only those metabolites present in at least $80 \%$ of either the Fe-deficient or the control samples were considered. Significant changes in metabolite levels with Fe deficiency were detected for each plant species and tissues using one-factor analysis of variance (ANOVA; $p \leq 0.05$ ). Metabolite response ratios were defined as the level in the Fe deficiency treatment divided by the level in the Fe-sufficient controls; when ratios were lower than one the inverse was taken and the sign changed. Only metabolites with mean response ratios (using non- $\log _{10}$ transformed data) above 2.0 or below -2.0 were considered relevant and are discussed in this study. Multivariate analysis (supervised partial least square, PLS) was used to study the clustering of the Fe-deficient and control samples, as well as to find the set of metabolites responsible of the separation between samples. Correlations between selected metabolites were also analyzed, to reveal processes that may be consistently present in Fe-deficient materials.

\section{RESULTS}

Xylem sap and leaves were sampled from Fe-deficient plants and the corresponding Fe-sufficient controls shown in Figure 1. Xylem sap and whole leaf extract metabolite profiles were obtained by GC-MS, following the normalized procedures developed by Fiehn et al. (2008).

\section{XYLEM SAP METABOLITE PROFILES CHANGE WITH IRON DEFICIENCY}

The xylem sap from Fe-deficient and Fe-sufficient tomato, lupine, and peach tree plants was analyzed, taking into account only metabolites present in at least $80 \%$ of either Fe-deficient or $\mathrm{Fe}$ sufficient samples in each species. A total of 253, 233, and 251 of such consistently present metabolites were detected in tomato, lupine, and peach tree xylem sap, respectively. Using the Fiehn Lib database, 77,83 , and 77 of them were identified in tomato, lupine, and peach tree, respectively. Iron deficiency caused significant (at $p \leq 0.05$ ) changes in the levels of several of the identified metabolites (and also in some of the unknown ones, see below). Identified metabolites with mean response ratios above 2.0 (11, 3 , and 1 metabolites in tomato, lupine, and peach, respectively) or below $-2.0(32,16$, and 5 metabolites in tomato, lupine, and peach, respectively) are shown in Table 1 .

Most of the identified xylem sap metabolites decreased with Fe deficiency, with the largest decreases being found for polyamines such as putrescine ( 87 and 92\%) and spermidine (50 and 85\%) in tomato and lupine, respectively. Amino acids such as glycine, tyrosine, and alanine decreased (52-74\%) in both tomato and lupine xylem sap, whereas others decreased (50-80\%) only in tomato (lysine, leucine, isoleucine, valine, and serine) or lupine $(\beta$-alanine, tryptophan, and oxoproline). Decreases were also found for carbohydrates such as glucose-6-P and myo-inositol (in tomato and lupine) and 3-phosphoglyceraldehyde (PGA; in lupine and peach tree), whereas other carbohydrates only decreased in tomato (arabinose, inulobiose, fructose, galactinol, and sucrose), lupine (trehalose), or peach tree (gluconic acid). Regarding those xylem sap metabolites that increased with $\mathrm{Fe}$ deficiency, the highest increases were found for the TCA cycle organic acids aconitic (2.6- and 2.8-fold) and succinic (2.4- and 4.7-fold; in tomato and lupine, respectively), and citric, malic, and 2-oxoglutaric (in tomato). Some xylem sap amino acids and $\mathrm{N}$ related compounds showed large increases (2.5- to 7.1-fold) either in tomato (suberyl glycine, tryptophan, hydroxyglutaric acid, and asparagine) or in both tomato and lupine (maleic acid). In peach tree xylem sap, the only metabolite that increased more than twofold was the non-proteinogenic amino acid nicotianamine (NA).

On the other hand, Fe deficiency caused significant changes (at $p \leq 0.05$ ) in 17,29 , and 9 unknown metabolites in tomato, lupine, and peach tree xylem sap, respectively (Table A1 in Appendix; only unknowns consistently present in at least $80 \%$ of either $\mathrm{Fe}$ deficient or Fe-sufficient plants in each species, and with response ratios $>2.0$ or $<-2.0$, were considered). These unknowns account for 28,60 , and $60 \%$ of the total metabolites changing significantly in response to Fe deficiency in tomato, lupine, and peach tree, respectively.

\section{XYLEM SAP METABOLITE LEVELS CLUSTER SEPARATELY IN IRON-DEFICIENT AND SUFFICIENT SAMPLES}

The clustering of metabolites was studied in each plant species using PLS analysis, including both the identified and unknown metabolites (Figures 2A-C). In the three species, Fe-deficient and Fe-sufficient samples were well separated in clusters, with the separation between the Fe-deficient and Fe-sufficient clusters being larger in tomato and lupine than in peach tree xylem sap. The first vector (v1) explained 53,38, and $13 \%$ of the variability in tomato, lupine, and peach tree xylem sap, respectively, with the second vector (v2) explaining between 15 and $9 \%$ of the variability.

The separation between clusters was associated with those metabolites with a large contribution (X-weight) to v1 (Table 2). In tomato, identified metabolites with high positive $\mathrm{X}$-weights were organic acids of the TCA cycle such as 2-oxoglutaric, malic, 2-hydroxyglutaric, citric, succinic, and aconitic, whereas those with large negative $\mathrm{X}$-weights were aminoacids (such as glycine), other N-related compounds (spermidine, putrescine), and carbohydrates (arabinose, galacturonic acid, xylose, and inulobiose). A similar pattern was found in lupine, where identified metabolites with large positive $\mathrm{X}$-weights were organic acids such as succinic, aconitic, fumaric, maleic, 2-oxoglutaric, and malic, whereas those with large negative $\mathrm{X}$-weights were aminoacids such as tryptophan, tyrosine, $\beta$-alanine, and oxoproline. In peach, identified metabolites with large positive $\mathrm{X}$-weights were carbohydrates (glucose, arabitol, and sucrose) and glycolysis related compounds (ribose and gluconic acid), whereas those with large negative X-weights were aminoacids and other N-related metabolites (2-hydroxyglutaric acid, proline), carbohydrates (galactinol and threonine), and some organic acids such as fumaric. Approximately $45 \%$ of the metabolites with a high contribution to cluster separation were unknowns (Table 2).

\section{LEAF EXTRACT METABOLITE PROFILES CHANGE WITH IRON DEFICIENCY}

Leaf extracts from Fe-deficient and Fe-sufficient tomato, sugar beet, and peach trees were analyzed, taking into account only metabolites present in at least $80 \%$ of either Fe-deficient or 
Table 1 | Main effects of iron deficiency on xylem sap metabolite levels.

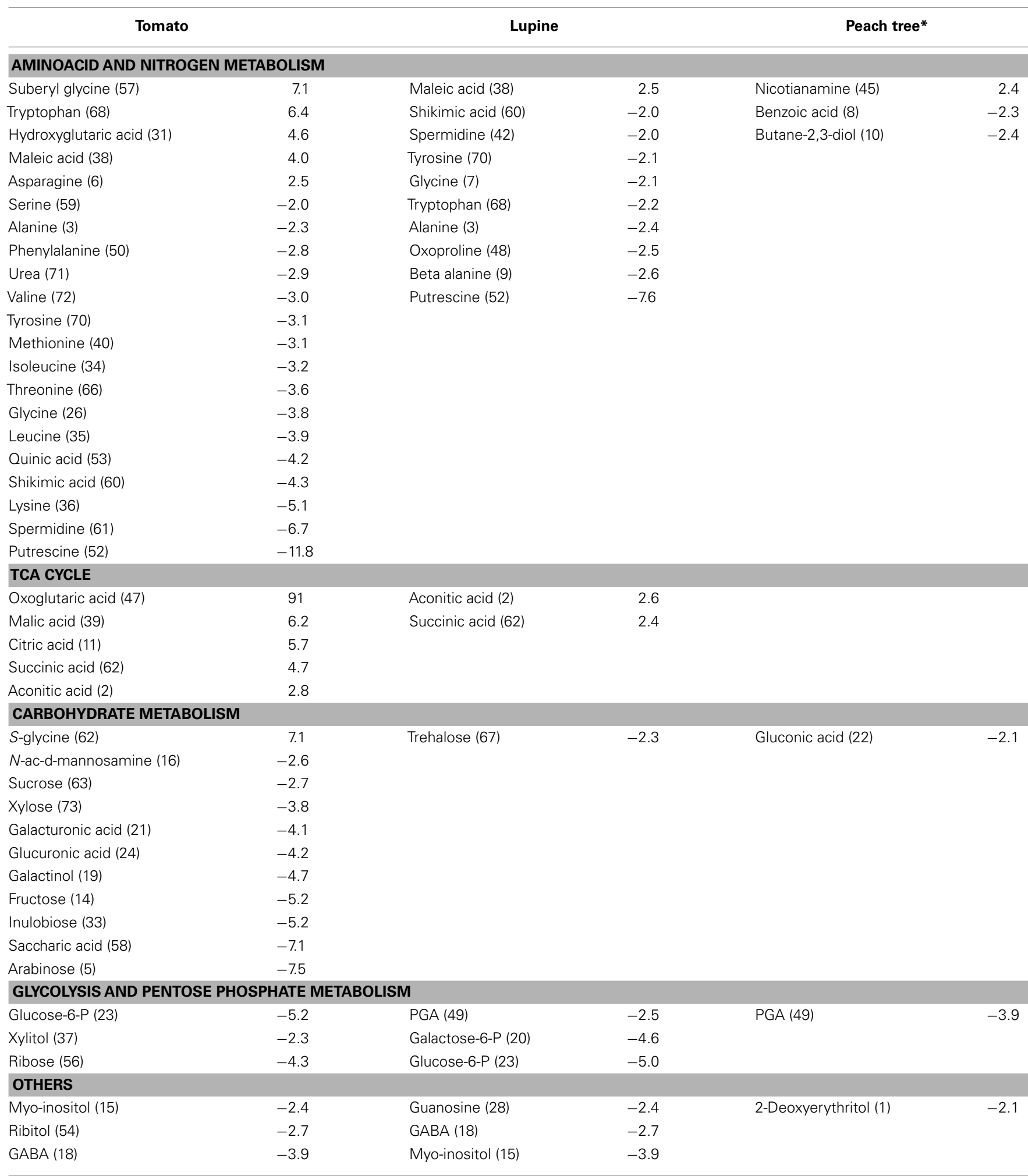

The corresponding response ratios, defined as the level in the -Fe treatment divided by the level in the +Fe treatment, are also shown. When the response ratio was

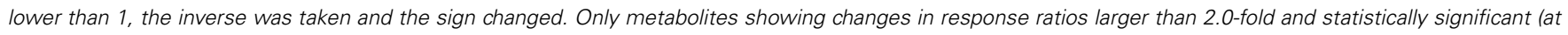
$p \leq 0.05)$ are included in the table. Numbers in brackets in each metabolite correspond to those shown in Figure 7.

* In peach trees, the response ratios correspond to levels with severe Fe deficiency vs. leaves with slight Fe deficiency. 


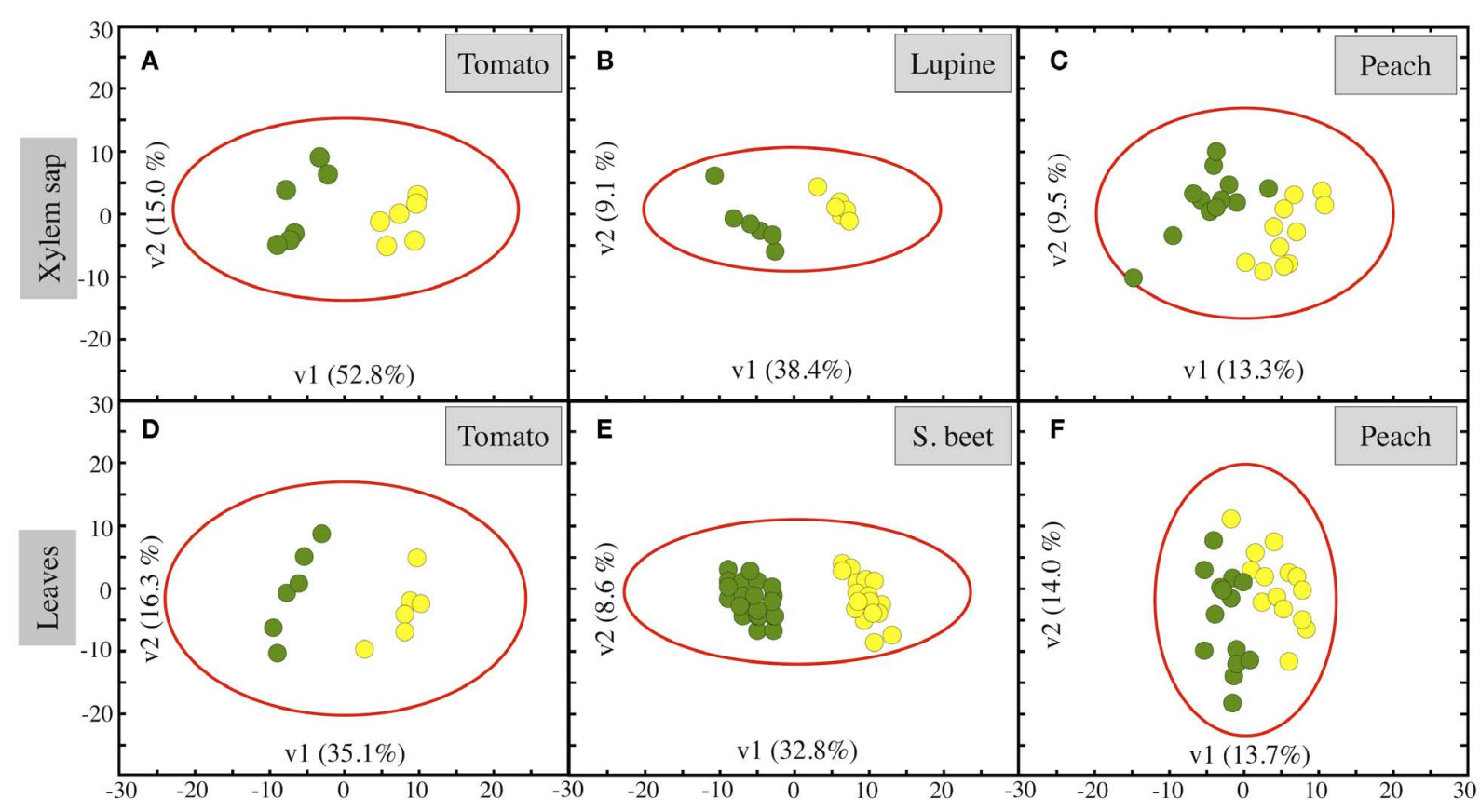

FIGURE 2 | Partial least square (PLS) analysis of xylem sap and leaf extract metabolites as affected by Fe deficiency. Score scatter plot of PLS vector 1 (v1) vs. PLS vector 2 (v2) of all detected metabolites (identified ones plus unknowns) in control (green circles) and Fe-deficient (yellow circles) samples. Xylem sap of (A) tomato, (B) lupine, and (C) peach tree. Leaf extracts of (D) tomato, (E) sugar beet, and (F) peach tree. The percentage of variability explained by each vector is indicated in parenthesis in the corresponding axes.
Fe-sufficient plants in each species. A total of 254, 113, and 239 metabolites were consistently present in leaf extracts of tomato, sugar beet, and peach tree, respectively. Using the Fiehn Lib database, 65, 82, and 92 metabolites were identified in leaf extracts of tomato, sugar beet, and peach tree, respectively. Iron deficiency caused significant (at $p \leq 0.05$ ) changes in the levels of several identified metabolites (and also in those of some unknowns, see below). Metabolites identified in leaf extracts with mean response ratios above $2.0(12,29$, and 4 metabolites in tomato, sugar beet, and peach, respectively) or below $-2.0(8,4$, and 3 metabolites in tomato, sugar beet, and peach, respectively) are shown in Table 3.

Most of the metabolites identified in leaf extracts increased with Fe deficiency, with major ( $>5$-fold) increases in aminoacids and $\mathrm{N}$-related compounds, including glutamine (33-fold), serine (20-fold), isoleucine (14-fold), valine (ninefold), oxoproline (eightfold), leucine (eightfold), glycine (sevenfold), tyrosine (sixfold), and threonine (sixfold) in sugar beet, and suberyl glycine (sixfold) in peach tree. Moderate increases (between two- and fivefold) were found for glutamic acid and alanine in sugar beet, for tyrosine, ethanolamine, tryptophan, and leucine in tomato, and for asparagine and isoleucine in peach tree. Also, other leaf metabolites increased with Fe deficiency in tomato and/or sugar beet, including TCA cycle components (citric, succinic, and fumaric acids, increasing 3- to 14-fold), and carbohydrates (e.g., $N$-acetyl-D-hexosamine and $N$-acetyl-D-mannosamine, increasing two- to six-fold). Only a few leaf extract metabolites decreased with Fe deficiency, most of them in tomato, including aminoacids and $\mathrm{N}$-related compounds (hydroxylamine, homoserine, aspartic acid, and glutamine, decreasing by $93,82,61$, and $54 \%$, respectively), and other metabolites such as hydroxycarbamate (decreasing by $87 \%$ ). Other compounds that decreased were phytol and oxalic acid in sugar beet (decreases of 74 and $82 \%$, respectively) and gluconic acid in peach (58\% decrease).

On the other hand, Fe deficiency caused significant changes (at $p \leq 0.05$ ) in 16,25 , and 1 unknown metabolites in tomato, sugar beet, and peach tree leaf extracts, respectively (Table A2 in Appendix; only unknowns consistently present in at least $80 \%$ of either Fe-deficient or Fe-sufficient plants in each species, and with response ratios $>2.0$ or $<-2.0$, were considered). These unknown metabolites account for 44,43 , and $13 \%$ of the total metabolites changing significantly in response to Fe deficiency in tomato, sugar beet, and peach tree leaf extracts, respectively.

\section{LEAF EXTRACT METABOLITE LEVELS CLUSTER SEPARATELY IN IRON-DEFICIENT AND SUFFICIENT SAMPLES}

The clustering of metabolites in leaf extracts was studied in each plant species using PLS analysis, including both the identified metabolites and unknowns (Figures 2D-F). In the three species, Fe-deficient and control samples were separated in clusters, with the separation between the Fe-deficient and Fe-sufficient clusters being larger in tomato and sugar beet than in peach tree leaf extracts. The first vector (v1) explained 35, 33, and $14 \%$ of the variability in tomato, sugar beet, and peach tree, respectively, with the second vector (v2) explaining between 16 and $9 \%$ of the variability.

The separation between clusters was associated with those metabolites with a large contribution (X-weight) to v1 (Table 4). In tomato leaf extracts, identified metabolites with 
Table 2 | Metabolite X-weights in the partial least square (PLS) analysis of xylem sap shown in Figure 2.

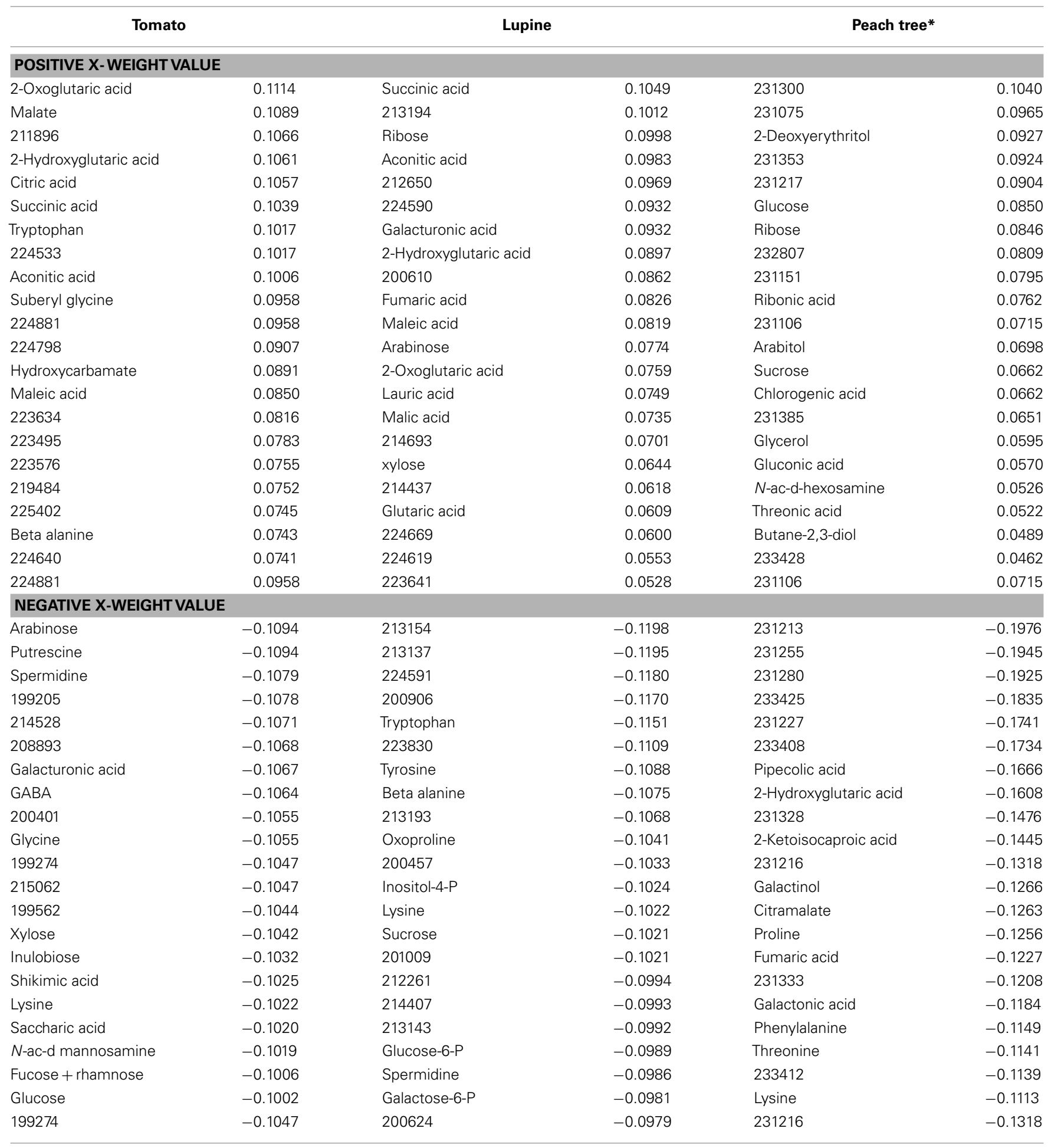

The $X$-weight values indicate the relative weight of each variable in the explanation of the discrimination between the two groups $(+F e$ and $-F e)$ in each plant species. *In peach trees, the $+\mathrm{Fe}$ and $-\mathrm{Fe}$ groups correspond to a slight and a severe Fe deficiency, respectively.

high positive X-weights were aminoacids and N-related com- negative X-weights were carbohydrates (fucose + rhamnose, pounds (hydroxylamine, homoserine, citrulline, aspartic acid, $N$-acetyl-D-hexosamine, $N$-acetyl-D-mannosamine, and myocyclohexylamine, and glutamine), whereas those with large inositol), as well as aminoacids and other N-related compounds 
Table 3 | Main effects of iron deficiency on leaf extract metabolite levels.

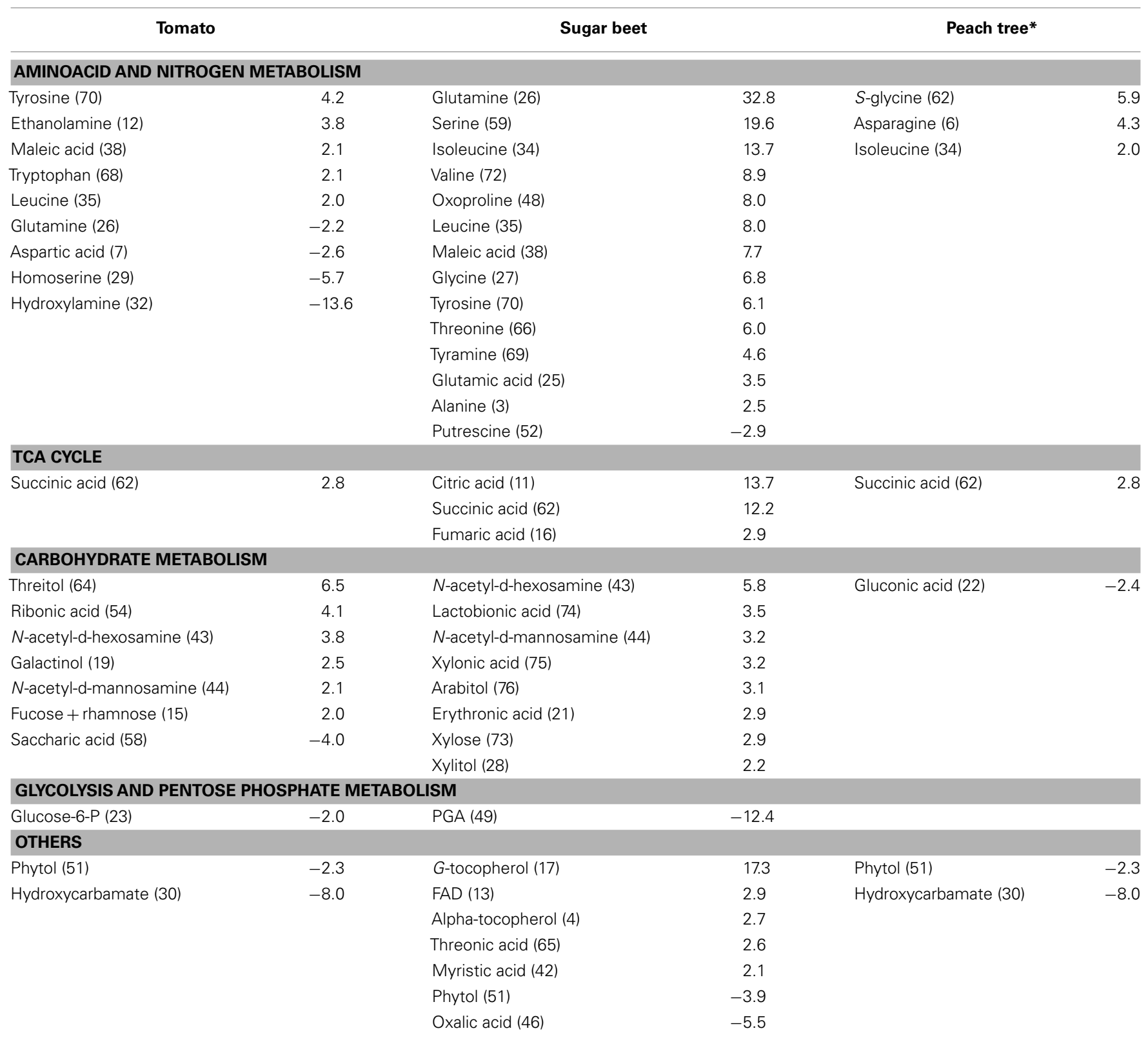

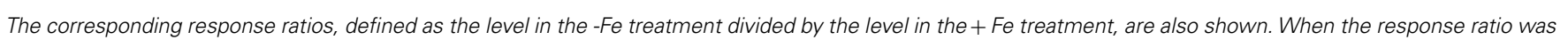

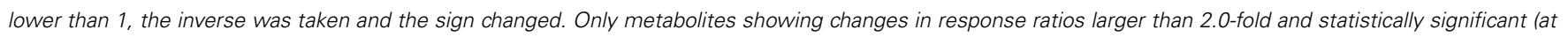
$p \leq 0.05)$ are included in the table. Numbers in brackets in each metabolite correspond to those shown in Figure $\mathbf{7}$.

* In peach trees, the response ratios correspond to levels with severe Fe deficiency vs. leaves with slight Fe deficiency.

(tyrosine, leucine, 2-isopropylmalic acid, and glutamic acid). In sugar beet leaf extracts, identified metabolites with high positive Xweights included organic acids (succinic and citric), carbohydrates (lactobionic acid, xylitol, $N$-acetyl-D-hexosamine, and $N$-acetylD-mannosamine), and aminoacids (oxoproline, serine, and threonine), whereas metabolites with high negative $\mathrm{X}$-weights were glycolysis and pentose phosphate pathway related compounds (PGA, fructose-6-P, and glucose-6-P), aminoacids and other $\mathrm{N}$ related compounds (putrescine and aspartic acid). In the case of peach tree leaf extracts, identified metabolites with high positive X-weights included aminoacids and N-related compounds (e.g., isoleucine, asparagine, serine, phenylalanine, or threonine), whereas those with high negative $\mathrm{X}$-weights included carbohydrates (erythronic acid and erythrose) as well as glycolysis and pentose phosphate pathway related compounds (gluconic acid and PGA). Between 39\% (in sugar beet) and 52\% (in tomato and peach) of the metabolites with high contribution to cluster separation were unknowns (Table 4). 
Table 4 | Metabolite X-weights in the partial least square (PLS) analysis of leaf extracts shown in Figure 2.

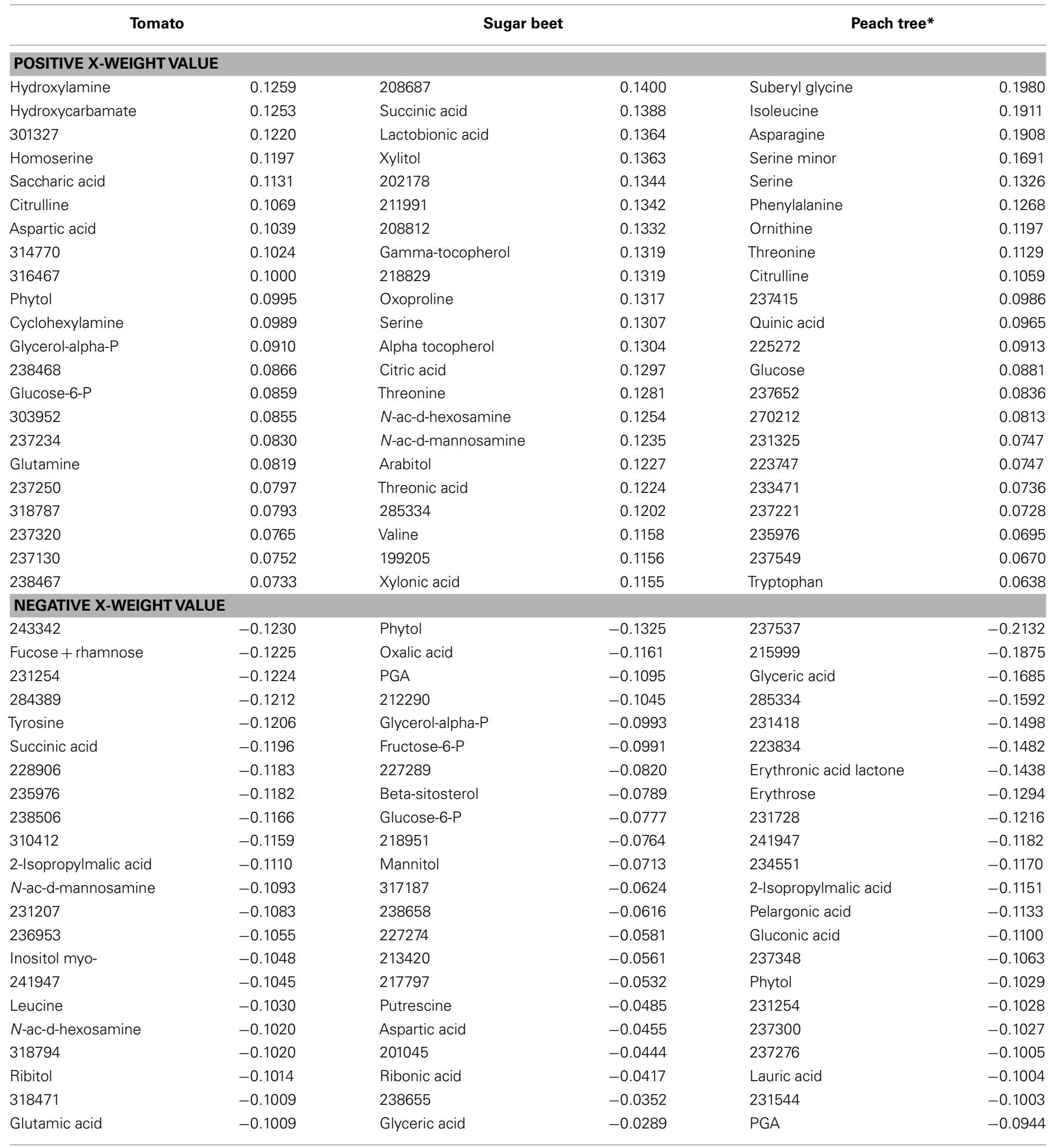

The $X$-weight values indicate the relative weight of each variable in the explanation of the discrimination between the two groups $(+F e$ and $-F e)$ in each plant species. *In peach trees, the response ratios correspond to levels with severe Fe deficiency vs. leaves with slight Fe deficiency.

CORRELATIONS BETWEEN METABOLITES CONTRIBUTING MARKEDLY TO LEAF EXTRACT METABOLITE CLUSTER SEPARATION

Carboxylates, aminoacids, and N-related compounds were consistently major contributors to cluster separation in Fe-deficient and Fe-sufficient leaf extracts in the three species studied (Figures 2D-F; Table 4). Aminoacids and carboxylates are linked through different deamination reactions (Owen et al., 2002), which can contribute to provide $\mathrm{C}$ skeletons to the TCA cycle 


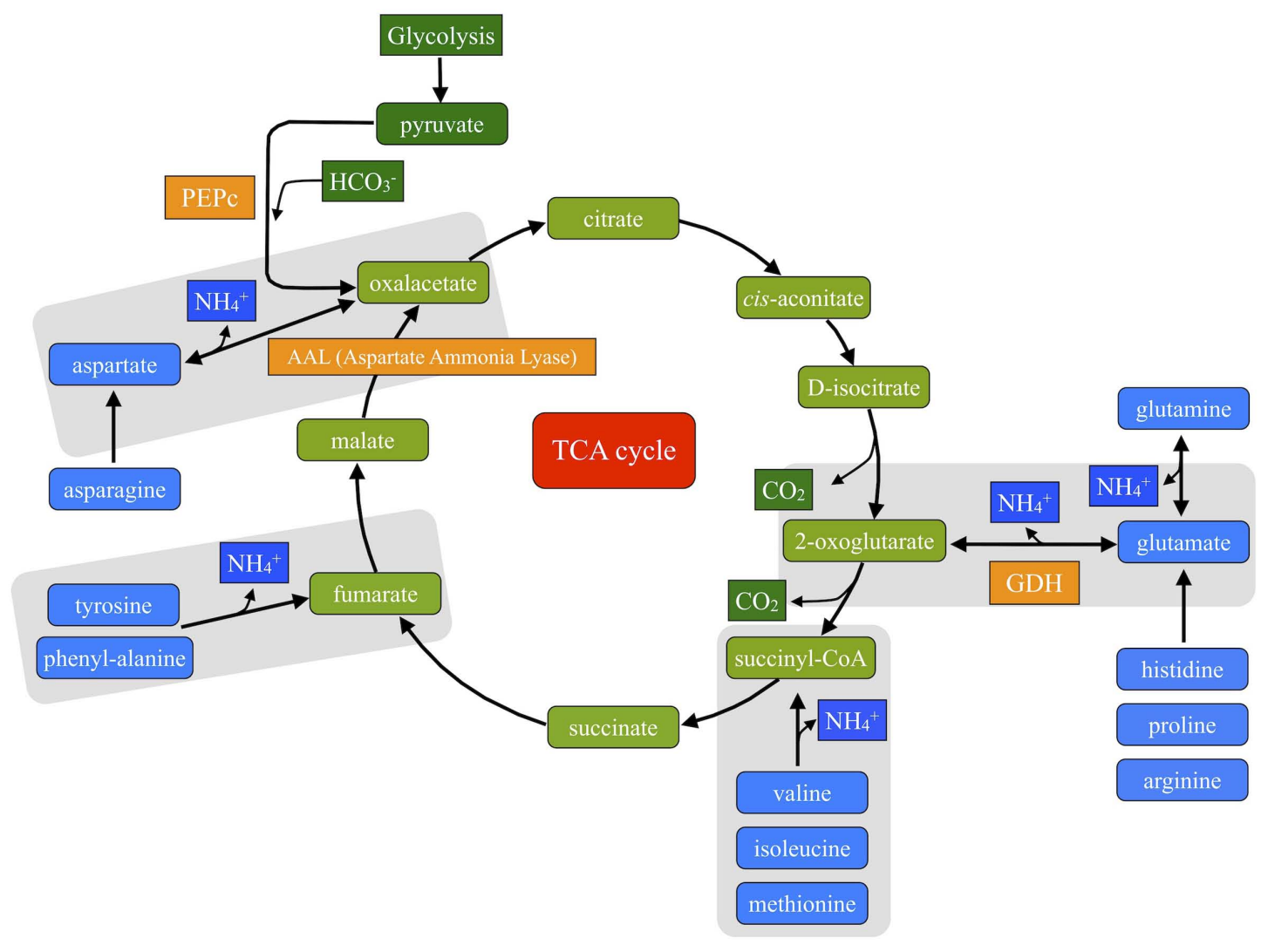

FIGURE 3 | Anaplerotic reactions feeding the TCA cycle. Reactions where aminoacids play a role as a C source are highlighted in gray.

(Figure 3). We explored the correlations between specific metabolites involved in such reactions in all three species and in the two Fe treatments. In the Fe-sufficient samples, positive correlations between the levels of aminoacids and organic acids were found, whereas in the Fe-deficient samples the correlations were negative: the correlations between (i) aspartic acid vs. citric acid, (ii) glutamic acid vs. 2-oxoglutaric acid, and (iii) tyrosine vs. fumaric acid in Fe-deficient and Fe-sufficient sugar beet leaf extracts are shown in Figure 4. Similar correlations were found for the pair aspartate/citric acid in tomato and peach leaf extracts, although in the latter case the correlation was weaker (data not shown).

\section{CHANGES IN XYLEM SAP METABOLITE PROFILES AND CLUSTERING DURING IRON RESUPPLY TO IRON-DEFICIENT TOMATO PLANTS}

The xylem sap Fe concentrations increased rapidly after Fe resupply to Fe-deficient plants (from 5 to $74,177,156$, and $66 \mu \mathrm{M}$ Fe at $6,12,18$, and $24 \mathrm{~h}$ after Fe resupply, respectively; Figure 5). In Fesufficient plants, xylem sap Fe concentrations remained constant at approximately 10-20 $\mu \mathrm{M}$ throughout the experiment (Figure 5). A total of 253 metabolites were found consistently (in at least $80 \%$ of the samples in at least a sampling time). Using the Fiehn Lib database, 77 metabolites were identified (Table 5). Iron resupply caused significant (at $p \leq 0.05$ ) changes in the levels of several identified metabolites and also in those of some unknowns (see below). At each sampling time, response ratios were obtained using the data from the Fe-resupplied plants and the corresponding $\mathrm{Fe}$ sufficient control ones, to dismiss metabolite profile changes due to circadian rhythms not affected by Fe resupply. All identified metabolites with mean response ratios above $2.0(14,11,11$, and 4 metabolites at $6,12,18$, and $24 \mathrm{~h}$ after resupply, respectively) or below $-2.0(24,16,9$, and 3 metabolites at $6,12,18$, and $24 \mathrm{~h}$ after resupply, respectively) are shown in Table 5.

Many of the xylem sap metabolites that decreased with $\mathrm{Fe}$ deficiency (21 out of 32 ) were still affected at a similar level $6 \mathrm{~h}$ after Fe resupply (50-83\% decreases with respect to the control). These included aminoacids and $\mathrm{N}$-related compounds such as leucine, putrescine, lysine, valine, tyrosine, and isoleucine, as well as carbohydrates such as glucose, arabinose, fructose, and inulobiose. However, $6 \mathrm{~h}$ after Fe resupply, large significant increases (at $p \leq 0.05$ ) were found for citric, maleic, fumaric, and aspartic acids when compared to Fe-deficient plants. Increases (although not significant at $p \leq 0.05$ ) also occurred for other TCA cycle metabolites (2-oxoglutaric, malic, and aconitic acids). After this time point, the xylem sap metabolite profiles tended progressively toward those of the controls. The only exceptions were aconitic, citric, and 2-oxoglutaric acids, that $18 \mathrm{~h}$ after resupply showed levels still higher than those present in the controls. After $24 \mathrm{~h}$ of Fe resupply, only two of the metabolites, aconitic, and citric acids, were still present at levels higher than those found in the controls. 

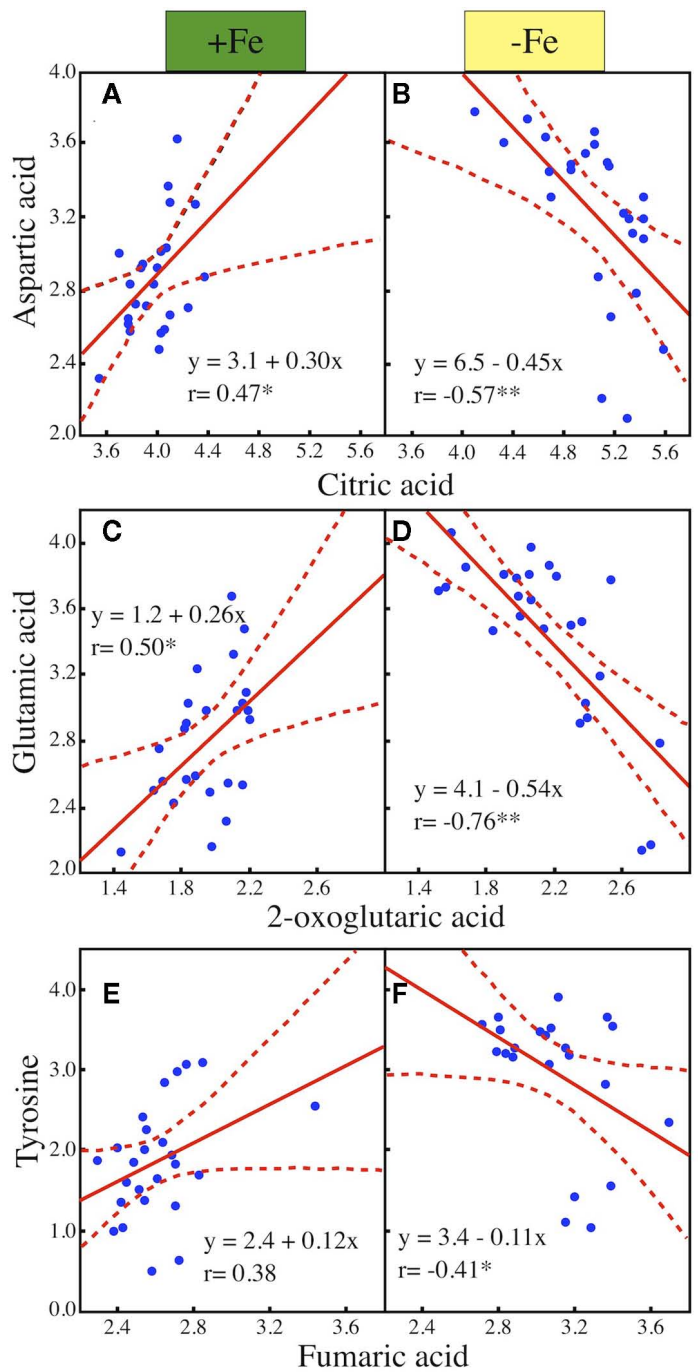

FIGURE 4 | Correlations between the sugar beet leaf extract levels of selected organic acids and aminoacids involved in anaplerotic reactions as affected by Fe deficiency. Pearson's coefficients of correlation $\left({ }^{*} p<0.05,{ }^{*} p<0.01\right)$ and regression equations are indicated in each graph. (A) Aspartic acid vs. citric acid in Fe-sufficient plants. (B) Aspartic acid vs. citric acid in Fe-deficient plants. (C) Glutamic acid vs. 2-oxoglutaric acid in Fe-sufficient plants. (D) Glutamic acid vs. 2-oxoglutaric acid in Fe-deficient plants. (E) Tyrosine vs. fumaric acid in Fe-sufficient plants. (F) Tyrosine vs. fumaric acid in Fe-deficient plants.

Regarding metabolite clustering, all xylem samples from Fesufficient plants (and at all sampling times) were grouped in a single cluster, whereas samples from Fe-deficient and Fe-resupplied plants obtained at different sampling times clustered into separate groups (Figure 6). The metabolites responsible for cluster separation were similar to those found for $+\mathrm{Fe}$ and $-\mathrm{Fe}$ samples. The cluster of samples taken $6 \mathrm{~h}$ after Fe resupply was close to that of samples from Fe-deficient plants, whereas the cluster of samples taken $24 \mathrm{~h}$ after Fe resupply was close to that of Fe-sufficient samples. The clusters of samples taken 12 and $18 \mathrm{~h}$ after resupply were in intermediate positions.

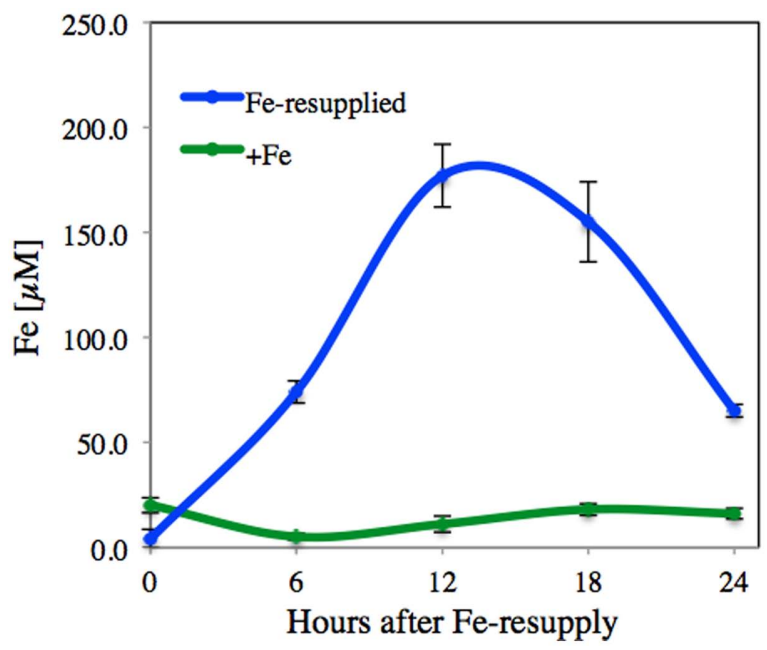

FIGURE 5 |Time-course of the Fe concentrations in the xylem sap of Fe-deficient tomato plants after Fe resupply. Iron-deficient tomato plants were resupplied with Fe(III)-EDTA $45 \mu \mathrm{M}$, and xylem sap was taken at 0, 6, 12,18 , and $24 \mathrm{~h}$ after Fe resupply. Six different plants were sampled at each sampling time. Data are means $\pm \mathrm{SD}$.

\section{DISCUSSION}

We have studied the changes in metabolite profiles of xylem sap and whole leaf extracts of several Strategy I plant species as affected by Fe deficiency. Iron deficiency led to consistent alterations in the metabolite profiles of both xylem sap and whole leaf extracts of plants grown in controlled environments, although changes found in the field-grown peach trees used were less marked (see below). In all species, the main classes of compounds affected were TCA cycle metabolites, $\mathrm{N}$ compounds, and carbohydrates. Xylem sap and leaf extract metabolites showing changes with Fe deficiency were assigned to metabolic pathways as indicated in Figure 7.

\section{EFFECTS OF IRON DEFICIENCY ON XYLEM SAP METABOLITE PROFILES}

The levels of xylem sap aminoacids and other N-related compounds, as well as those of carbohydrates, decreased markedly in tomato and lupine in response to Fe deficiency. No data are available, to the best of our knowledge, on the xylem sap amino acid levels in Fe-deficient plants, although in sugar beet leaf apoplastic fluid the total concentration of aminoacids increased with $\mathrm{Fe}$ deficiency (López-Millán et al., 2000b). Nitrogen storage-related compounds such as putrescine and spermidine showed the largest decreases among the xylem sap N-related compounds, and this could be associated with the decreases in aminoacids, since the concentration of both types of compounds is generally correlated in plants (Mattoo et al., 2010). Xylem sap carbohydrates decreased in response to Fe deficiency in the three species studied. Although this is not in agreement with previous results in sugar beet xylem sap (López-Millán et al., 2000b), it should be taken into account that xylem carbohydrate levels may be affected by xylem/phloem transfer processes, which are largely species dependent.

In contrast to the decreases in $\mathrm{N}$ compounds and carbohydrates, Fe deficiency led to marked increases in xylem sap TCA cycle organic acids, in agreement with previous studies with different 
Table 5 | Time-course of the changes in xylem sap metabolite levels during Fe resupply to Fe-deficient tomato plants.

\begin{tabular}{|c|c|c|c|c|c|}
\hline & $-\mathrm{Fe}$ & $6 \mathrm{~h}$ & $12 \mathrm{~h}$ & $18 \mathrm{~h}$ & $24 \mathrm{~h}$ \\
\hline \multicolumn{6}{|c|}{ AMINOACID AND NITROGEN METABOLISM } \\
\hline $\begin{array}{l}\text { 2-Hydroxyglutaric } \\
\text { acid (31) }\end{array}$ & $4.6 a$ & $5.9 a$ & $5.6 a$ & 3.7a & $2.3 a$ \\
\hline Alanine (3) & $-2.3 a$ & $-2.2 \mathrm{a}$ & $-2.3 a$ & $-1.7 a$ & $-1.6 a$ \\
\hline Adipic acid & $1.1 \mathrm{a}$ & $-3.2 \mathrm{a}$ & $-1.0 a$ & $5.1 a$ & $2.3 a$ \\
\hline Asparagine (6) & $2.5 a$ & $3.0 \mathrm{a}$ & $1.2 a$ & $3.1 \mathrm{a}$ & $1.9 a$ \\
\hline Aspartic acid & $1.7 \mathrm{~b}$ & $5.9 a$ & $1.7 b$ & $-1.2 b$ & $1.1 \mathrm{~b}$ \\
\hline Beta alanine & $1.5 b$ & $1.8 \mathrm{ab}$ & $2.3 a$ & $1.4 \mathrm{~b}$ & $1.3 b$ \\
\hline Glutamic acid & $-1.2 b$ & 3.5a & $1.6 b$ & $1.5 b$ & $1.3 b$ \\
\hline Glutamine & $-1.4 b$ & $-1.2 b$ & $-1.6 b$ & $2.1 \mathrm{a}$ & $1.5 a b$ \\
\hline Glycine (26) & $-3.8 \mathrm{c}$ & $-2.7 b c$ & $-2.1 b c$ & $-2.0 \mathrm{ab}$ & $-1.5 a$ \\
\hline Isoleucine (34) & $-3.2 b$ & -4.5 & $-1.4 a b$ & $1.2 a$ & $1.2 \mathrm{a}$ \\
\hline Leucine (35) & $-3.9 b$ & $-5.5 b$ & $-1.2 \mathrm{ab}$ & $1.1 \mathrm{ab}$ & $1.5 a$ \\
\hline Lysine (36) & $-5.1 b$ & $-4.9 b$ & $-2.0 b$ & $1.4 a$ & $1.2 \mathrm{a}$ \\
\hline Maleic acid (38) & $4.0 \mathrm{~b}$ & $19.2 \mathrm{a}$ & $3.9 b$ & $2.4 b$ & $2.1 \mathrm{~b}$ \\
\hline Methionine (40) & $-3.1 \mathrm{a}$ & $-2.2 \mathrm{a}$ & $-1.4 a$ & $-1.3 a$ & $-1.3 a$ \\
\hline Quinic acid (53) & $-4.2 \mathrm{c}$ & $-1.7 \mathrm{ab}$ & $-2.7 b c$ & $-1.1 \mathrm{a}$ & $-1.4 a$ \\
\hline Phenylalanine (50) & $-2.8 b$ & $-2.2 b$ & $-1.4 a b$ & $-1.1 \mathrm{ab}$ & $1.2 \mathrm{a}$ \\
\hline Putrescine (52) & $-11.8 b$ & $-5.2 b$ & $-3.3 b$ & $-2.1 a b$ & $-1.3 a$ \\
\hline Shikimic acid (60) & $-4.3 c$ & $-2.2 \mathrm{bc}$ & $-2.6 c$ & $-1.3 a$ & $-1.5 a b$ \\
\hline Serine (59) & $-2.0 b$ & $1.1 \mathrm{a}$ & $-1.6 a b$ & $-2.4 b$ & $-1.2 \mathrm{ab}$ \\
\hline Spermidine (61) & $-6.7 c$ & $-2.0 \mathrm{ab}$ & $-3.0 \mathrm{bc}$ & $-2.0 \mathrm{ab}$ & $-1.6 a$ \\
\hline Suberyl glycine (57) & $7.1 \mathrm{a}$ & $1.4 \mathrm{~b}$ & $2.1 \mathrm{~b}$ & $2.4 \mathrm{~b}$ & $1.2 b$ \\
\hline Threonine (66) & $-3.6 b$ & $-3.8 b$ & $-2.3 a b$ & $-1.1 a$ & $-1.1 \mathrm{a}$ \\
\hline Tryptophan (68) & $6.4 \mathrm{~b}$ & $5.1 \mathrm{~b}$ & $2.7 \mathrm{~b}$ & $14.1 \mathrm{a}$ & $3.4 \mathrm{~b}$ \\
\hline Tyramine & $-1.5 b$ & $-1.3 b$ & $-4.6 b$ & $5.2 \mathrm{a}$ & $1.7 b$ \\
\hline Tyrosine (70) & $-3.1 b$ & $-4.6 b$ & $1.0 a b$ & $1.5 a b$ & $2.4 a$ \\
\hline Urea (71) & $-2.9 a$ & $-3.2 \mathrm{a}$ & $-1.3 a$ & $-1.2 a$ & $1.4 a$ \\
\hline Valine (72) & $-3.0 b$ & $-5.1 b$ & $-1.4 a b$ & $1.1 \mathrm{a}$ & $1.4 a$ \\
\hline \multicolumn{6}{|l|}{ TCA CYCLE } \\
\hline Aconitic acid (2) & $2.8 \mathrm{~b}$ & $5.3 a b$ & $6.5 a$ & 4.5ab & $3.7 b$ \\
\hline $\begin{array}{l}\text { 2-Oxoglutaric acid } \\
\text { (47) }\end{array}$ & 91b & $123 a b$ & $165 a$ & $15 \mathrm{c}$ & $31.3 c$ \\
\hline Citric acid (11) & $5.7 \mathrm{c}$ & $29.4 a$ & $14.4 \mathrm{~b}$ & $18.4 b$ & $6.7 \mathrm{c}$ \\
\hline Fumaric acid (16) & $1.8 b$ & $7.4 a$ & $3.2 b$ & $2.7 b$ & $1.7 \mathrm{~b}$ \\
\hline Malic acid (39) & $6.2 \mathrm{a}$ & $11.7 a$ & $6.2 a$ & $6.8 \mathrm{a}$ & $4.3 a$ \\
\hline Succinic acid (62) & $4.7 a$ & $5.7 a$ & $3.6 a$ & $4.5 a$ & $2.2 a$ \\
\hline \multicolumn{6}{|c|}{ CARBOHYDRATE METABOLISM } \\
\hline Arabinose (5) & $-7.5 \mathrm{c}$ & $-5.3 b c$ & $-5.1 b c$ & $-3.4 a b$ & $-2.5 a$ \\
\hline Fructose (14) & $-5.2 b$ & $-5.2 b$ & $-6.9 b$ & $-1.9 a$ & $-3.0 \mathrm{ab}$ \\
\hline Galactinol (19) & $-4.7 b$ & $-1.5 a b$ & $-1.9 a b$ & $-1.1 \mathrm{a}$ & $-1.0 a$ \\
\hline $\begin{array}{l}\text { Galacturonic acid } \\
\text { (21) }\end{array}$ & $-4.1 \mathrm{c}$ & $-2.4 b c$ & $-2.5 b c$ & $-1.5 a$ & $-1.6 a b$ \\
\hline Glucuronic acid (24) & $-4.2 b$ & $-2.6 b$ & $-2.5 b$ & $-1.6 b$ & $1.8 \mathrm{a}$ \\
\hline Inulobiose (33) & $-5.2 \mathrm{c}$ & $-3.7 b c$ & $-3.5 b c$ & $-2.1 \mathrm{a}$ & $-2.7 a b$ \\
\hline $\begin{array}{l}N \text {-acetyl-d- } \\
\text { mannosamine } \\
\text { (16) }\end{array}$ & $-2.6 \mathrm{c}$ & $1.0 a$ & $-1.4 b$ & $-2.1 b c$ & $-1.5 b$ \\
\hline Saccharic acid (58) & $-7.1 \mathrm{c}$ & $-1.4 a$ & $-2.7 b c$ & $-2.0 \mathrm{ab}$ & $-1.6 a b$ \\
\hline Sucrose (63) & $-2.7 \mathrm{c}$ & $1.0 a b$ & $-1.2 b$ & $1.4 a$ & $-1.2 b$ \\
\hline Xylose (73) & $-3.8 \mathrm{c}$ & $-1.5 a b$ & $-1.9 b c$ & $1.0 a$ & $-1.5 \mathrm{ab}$ \\
\hline
\end{tabular}

Table 5 | Continued

$-\mathrm{Fe} \quad 6 \mathrm{~h} \quad 12 \mathrm{~h} \quad 18 \mathrm{~h} \quad 24 \mathrm{~h}$

\begin{tabular}{|c|c|c|c|c|c|}
\hline \multicolumn{6}{|c|}{ GLYCOLYSIS AND PENTOSE PHOSPHATE PATHWAY } \\
\hline Glucose (23) & $-5.2 b$ & $-6.0 b$ & $-6.0 b$ & $-1.5 a$ & $-2.8 b$ \\
\hline Lactic acid & $-1.2 a$ & $-2.2 a$ & $1.3 a$ & $-1.2 a$ & $-1.2 \mathrm{a}$ \\
\hline Lyxitol (37) & $-2.3 a$ & $-1.5 a$ & $-1.9 a$ & $1.3 a$ & $2.2 \mathrm{a}$ \\
\hline Ribose (56) & $-4.3 \mathrm{c}$ & $-1.8 b c$ & $-2.1 b c$ & $1.4 a$ & 1.1ab \\
\hline \multicolumn{6}{|l|}{ SIGNALING } \\
\hline GABA (18) & $-4.4 \mathrm{c}$ & $-2.8 b c$ & $-2.8 b c$ & $-1.8 \mathrm{ab}$ & $-1.5 a$ \\
\hline Myo-inositol (15) & $-2.5 c$ & $-1.1 b c$ & $-1.2 b c$ & $1.5 a$ & $1.2 \mathrm{ab}$ \\
\hline \multicolumn{6}{|l|}{ OTHERS } \\
\hline Dihydroabietic acid & $4.2 \mathrm{a}$ & $1.2 \mathrm{a}$ & $1.7 a$ & $-2.2 a$ & $2.0 a$ \\
\hline Phosphoric acid & $1.1 \mathrm{~b}$ & $3.7 a$ & $-1.8 b$ & $-2.2 b$ & $-1.4 b$ \\
\hline Ribitol (54) & $-4.1 \mathrm{c}$ & $-2.2 b c$ & $-2.2 b c$ & $-1.1 a b$ & $1.1 \mathrm{a}$ \\
\hline
\end{tabular}

Resupply times were 6, 12, 18, and $24 \mathrm{~h}$. Response ratios are defined as the level in the -Fe treatment or Fe resupply divided by the level in the +Fe treatment at the same sampling time. When the response ratio was lower than 1, the inverse was taken and the sign changed. Values in bold indicate significant differences $(p<0.05)$ with the corresponding controls. Different letters within the same row indicate significant differences (using a Duncan Test at $p \leq 0.05$ ). Numbers in brackets correspond to those shown in Figure 7.

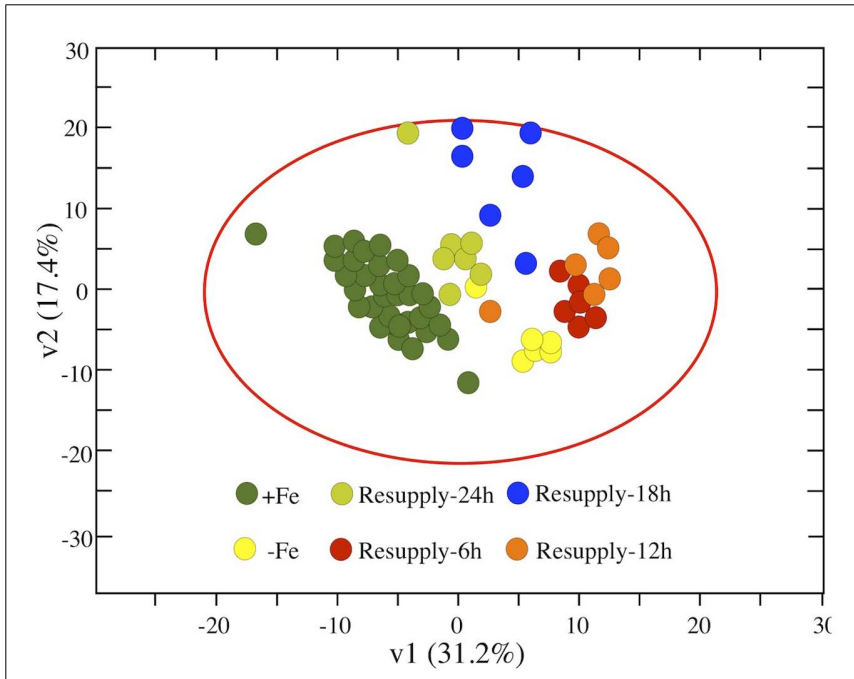

FIGURE 6 | Partial Least Square (PLS) analysis of tomato xylem sap metabolites as affected by Fe deficiency and resupply. Score scatter plot of PLS vector 1 ( $\mathrm{v} 1$ ) vs. PLS vector 2 ( $\mathrm{v} 2$ ) of all detected metabolites (identified ones plus unknowns) in xylem sap from Fe-sufficient plants (including all sampling times; dark green circles), Fe-deficient plants $(0 \mathrm{~h}$ after resupply; yellow circles), and Fe-deficient plants resupplied with $\mathrm{Fe}$ for 6 (red circles), 12 (orange circles), 18 (blue circles), and $24 \mathrm{~h}$ (light green circles). The percentage of variability explained by each vector is indicated in parenthesis in the corresponding axes.

plant materials and species (Abadía et al., 2002). For instance, 17to 24 -fold increases in citric acid were reported to occur in the xylem sap of Fe-deficient sugar beet (López-Millán et al., 2000b), tomato (López-Millán et al., 2009), and peach trees (Larbi et al., 2010). These increases have been attributed to the increases in the 
root activities of PEPC and TCA cycle enzymes induced by Fe deficiency (De Nisi and Zocchi, 2000; López-Millán et al., 2000a; Ollat et al., 2003). On the other hand, TCA cycle organic acids (mainly citric acid) can also play a role as xylem sap Fe carriers (RellánÁlvarez et al., 2010b). In Arabidopsis and rice, frd-type mutants unable to load sufficient citrate to the xylem show Fe deficiencylike symptoms (Durrett et al., 2007; Yokosho et al., 2009). It has been recently shown that citrate plays a key role in the mobilization of apoplastic Fe in different tissues in Arabidopsis (Roschzttardtz et al., 2011).

Most of the changes found in tomato and lupine xylem sap metabolite profiles were not found in peach trees grown in the field. This could be explained by the fact that the peach trees selected as controls at the beginning of the growth-season (and labeled initially as Fe-sufficient) became slightly Fe-deficient at sampling time. Therefore, the two peach samples used rather correspond to a slight Fe deficiency and a severe one. Also, it should be taken into account that the Fe-dependent metabolite profile changes could be substantially different in long-lived plants such as trees growing in the field and in young plants grown in controlled environments. The level of NA, a non-proteinogenic amino acid related with intracellular Fe trafficking (von Wirén et al., 1999), increased twofold in peach xylem sap when the Fe deficiency was severe. This may suggest that NA could play a role in long-distance Fe transport in peach trees, especially in severely deficient trees where the xylem organic acid concentrations could be very high (Larbi et al., 2010). The xylem sap pH in peach trees is approximately 6.5-7.5 (Larbi et al., 2003), and at this pH value NA can chelate efficiently $\mathrm{Fe}$, as it has been shown by in vitro experiments (Rellán-Álvarez et al., 2008). In the xylem sap of species such as sugar beet and tomato, which have a $\mathrm{pH}$ of approximately 5.5, citrate is thought to be the major Fe carrier (Rellán-Álvarez et al., 2010b), whereas NA is unlikely to play any role in xylem Fe transport (Rellán-Álvarez et al., 2008).

\section{EFFECTS OF IRON RESUPPLY ON THE METABOLITE PROFILE OF IRON-DEFICIENT TOMATO XYLEM SAP}

The PLS analysis shows the rapid changes in the xylem sap metabolite profile of Fe-resupplied plants, which disengages away from that of Fe-deficient plants and then moves, in a counterclockwise course, toward that of Fe-sufficient plants (Figure 6). Within $6 \mathrm{~h}$ of Fe resupply (when xylem Fe had increased approximately fourfold; Figure 5), the PLS analysis already indicates a clear detachment of the Fe-resupplied group from the Fe-deficient one. This includes a dramatic temporary increase in xylem sap TCA cycle metabolites (Table 5), with concentrations reaching values much higher than those present in the xylem sap of Fe-deficient plants. This temporary flush of carboxylates in the xylem may indicate that roots revert rapidly to a control situation by exporting the excess of organic acids toward the shoot. Twelve hours after Fe resupply (when the concentration of Fe in the tomato xylem sap had peaked), the group of resupplied plants detached from the 6-hresupplied plants, but were still far away from the Fe-sufficient control group. Eighteen hours after resupply the concentration of Fe was still in his peak, but the PLS analysis showed a shift of the group toward that of the Fe-sufficient controls. One day after Fe resupply, the xylem sap metabolite profile was very similar to that of Fe-sufficient plants. This suggests that the mechanisms for anaplerotic root $\mathrm{C}$ supply occurring in Fe-deficient plants had already ceased. This is in agreement with the $65 \%$ decrease of the root PEPC activity reported in sugar beet Fe-deficient plants after 1 day of Fe resupply (Abadía et al., 2011). Also, $24 \mathrm{~h}$ after Fe resupply the xylem transport of aminoacids and N-related compounds as well as that of carbohydrates had re-assumed levels similar to those occurring in the Fe-sufficient plants.

Changes in metabolite profiles with Fe resupply occur much faster that the leaf chlorosis recovery, since 1 day after Fe resupply the leaf chlorophyll increases were only minor ( $12 \%$ in sugar beet; Larbi et al., 2004). The occurrence of a lag-phase in re-greening after Fe resupply has also been described in different plant species (Nishio and Terry, 1983; Thoiron et al., 1997; López-Millán et al., 2001a; Larbi et al., 2006). By this time, and although the leaf chlorophyll level was still low, a significant increase in leaf photosynthetic rates and a marked relaxation of the violaxanthin pigment cycle toward the values found in the Fe-sufficient controls had already occurred (Larbi et al., 2004).

\section{LEAF EXTRACT METABOLITE PROFILES AS AFFECTED BY IRON DEFICIENCY}

The levels of aminoacids and other N-related compounds increased markedly in leaf extracts of tomato, sugar beet, and peach tree in response to Fe deficiency. Chlorosis induced by several factors (including Fe deficiency) was shown to increase leaf amino acid concentrations and decrease total protein content in several plant species (DeKock and Morrison, 1958). Increased levels of proteins related to proteolysis were also found in the roots of Fe-deficient sugar beet (Rellán-Álvarez et al., 2010a), cucumber (Donnini et al., 2010), and M. truncatula plants (Rodríguez-Celma et al., 2011). The increases in free leaf amino acid levels must result from processes occurring within the shoot, since Fe deficiency induces marked decreases in (i) root nitrite reductase activities (Rodríguez-Celma et al., 2011), (ii) xylem sap nitrate concentrations (López-Millán et al., 2000b), and (iii) xylem sap amino acid levels (Table 1). Therefore, the increase in leaf free aminoacids is likely to result from proteolysis processes occurring in the shoot. In barley and rice (two Strategy II species), Fe deficiency results in an accelerated senescence both in old leaves (Maruyama et al., 2005; Sperotto et al., 2007; Higuchi et al., 2011) and roots (Sperotto et al., 2008), leading to the hypothesis that aminoacids can be reutilized in young leaves of these plants (Higuchi et al., 2011). An Arabidopsis thylakoid proteomic study suggests that Fe-deficient leaves bear changes similar to those observed during senescence (Laganowsky et al., 2009). In senescent plants, it has been estimated that as much as $43 \%$ of the amino acids in young leaves can be supplied via phloem (Jeschke and Pate, 1991). The occurrence of substantial $\mathrm{N}$ recycling processes at the shoot level with Fe deficiency is supported by the markedly increased leaf levels of $\mathrm{N}$-carrier metabolites such as glutamine, glutamic acid, and asparagine (Table 3), occurring concomitantly with decreased leaf (and xylem sap) levels of $\mathrm{N}$-storage metabolites such as polyamines. One of the enzymes involved in the biosynthesis of polyamines ( $S$ adenosyl-L- methionine synthetase) was also found to decrease in roots of Fe-deficient M. truncatula (Rodríguez-Celma et al., 2011).

Along with the leaf increases in $\mathrm{N}$ compounds and carbohydrates, there was an increase in leaf TCA cycle metabolites, 


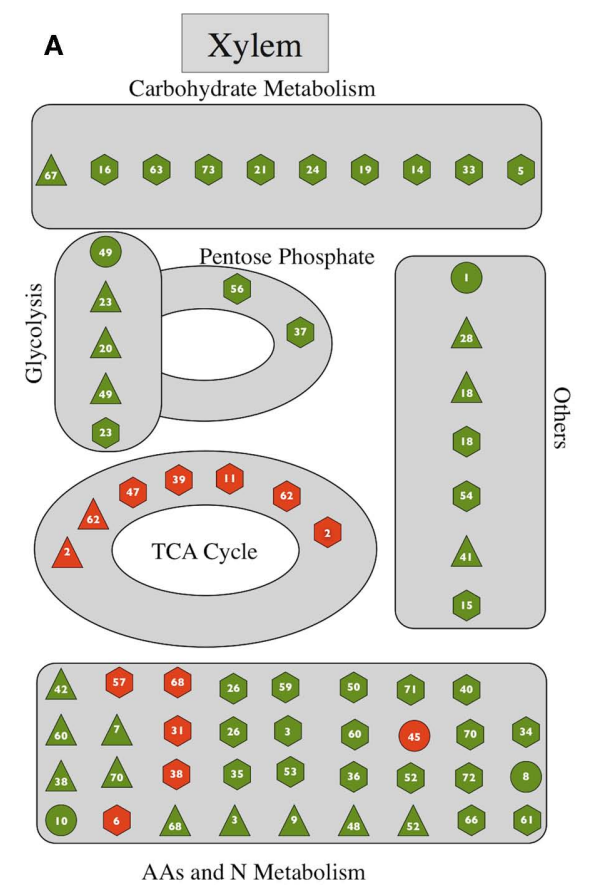

FIGURE 7 | Changes in metabolic pathways as affected by Fe deficiency (A) Xylem sap. (B) Leaf extracts. Red and green symbols indicate significant $(p \leq 0.01)$ increases and decreases, respectively. Octagon, circles, triangles,

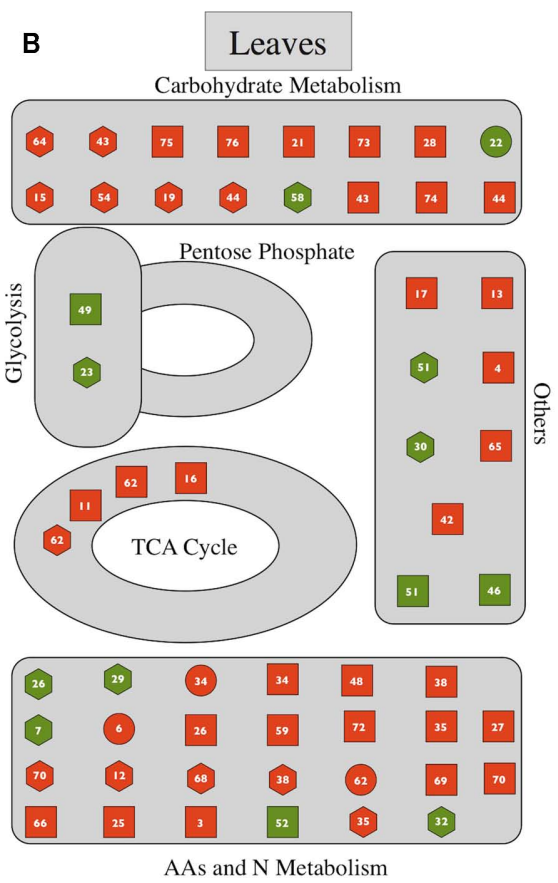

and squares are for tomato, sugar beet, lupine, and peach, respectively. The numbers inside each symbol correspond to metabolites shown in Tables 1 and 2. in agreement with previous data (López-Millán et al., 2001a,b; Abadía et al., 2002). This is in line with the high levels of carboxylates coming from the roots via xylem sap. The high concentration of organic acids in Fe-deficient leaves was not the result of increased TCA cycle and PEPC enzyme activities, since the activities of these enzymes did not change much with Fe deficiency in sugar beet, pear trees, and tomato (López-Millán et al., 2001a,b, 2009).

The scenario of Fe deficiency in leaves is construed by the need of $\mathrm{C}$ skeletons, due to the markedly reduced photosynthetic rates of the chlorotic foliage (Larbi et al., 2006). Carbon is fixed anaplerotically in the roots of Fe-deficient plants $C$ via PEPC and then transported to the leaves via xylem sap, helping to maintain basic metabolic processes such as respiration (López-Millán et al., 2000a,b). Results shown in this study support that additional anaplerotic reactions, using aminoacids as a $\mathrm{C}$ source, can also occur in the shoot of Fe-deficient plants. High correlations between selected pairs of aminoacids and TCA cycle metabolites involved in anaplerotic reactions were found in leaf extracts of three plant species, with the correlations being positive in $\mathrm{Fe}$ sufficient plants and negative in Fe-deficient ones (Figure 4). This suggests that the increased amino acid levels could generate carboxylates, and consequently increase the availability of $\mathrm{C}$ and $\mathrm{N}$ skeletons and reducing power through the reactions depicted in Figure 3. As suggested by Donnini et al. (2010), Fe-deficient plants would face a cellular effort similar to what occurs in mammal cells, which cannibalize muscle proteins to fulfill energetic needs when no carbohydrates are available and once the glycogen reserves are depleted. An open question that needs to be addressed is whether these anaplerotic reactions occur only in the young chlorotic leaves, or alternatively they also occur in old leaves, which are still green and therefore have normal photosynthetic rates, with both free aminoacids and carboxylates being translocated to the young leaves via phloem.

In summary, Fe deficiency leads to consistent changes in the xylem sap and leaf metabolite profiles of Strategy I plant species. In Fe-deficient plants the xylem contains increased levels of TCA cycle metabolites and decreased levels of aminoacids and carbohydrates, whereas in leaves the levels of both TCA cycle metabolites and aminoacids increase (Figure 7). These data suggest that in low photosynthesis, $\mathrm{C}$-starved Fe-deficient plants anaplerotic reactions can be crucial for survival in the short-term. Temporary alleviation of $\mathrm{C}$ shortage in these plants may be achieved not only through anaplerotic root $\mathrm{C}$ fixation via $\mathrm{PEPC}$, but also by local reutilization of $\mathrm{N}$ compounds to obtain $\mathrm{C}$ skeletons.

\section{ACKNOWLEDGMENTS}

This study was supported by the Spanish Ministry of Science and Innovation (MICINN; projects AGL2009-09018 and AGL201016515, co-financed with FEDER), the trilateral Project Hot Iron (ERA-NET Plant Genome Research KKBE; MICINN EUI200803618), the Spanish National Research Council (PA1000990, International Promotion Programme 2007), and the Aragón Government (group A03). Rubén Rellán-Álvarez and Hamdi El-Jendoubi were supported by MICINN-FPI grants. Authors thank Aurora Poc and Ade Calviño for assistance in growing plants, and Dr. AnaFlor López-Millán for helpful suggestions and carefully revising the manuscript. 


\section{REFERENCES}

Abadía, J. (1992). Leaf responses to iron nutrition - a review. J. Plant Nutr. $15,1699-1713$.

Abadía, J., López-Millán, A. F., Rombolà, A. D., and Abadía, A. (2002). Organic acids and Fe deficiency: a review. Plant Soil 241, 75-86.

Abadía, J., Vázquez, S., Rellán-Âlvarez, R., El-Jendoubi, H., Abadía, A., Álvarez-Fernández, A., and LópezMillán, A. F. (2011). Towards a knowledge-based correction of iron chlorosis. Plant Physiol. Biochem. 49, 471-482.

Álvarez-Fernández, A., Melgar, J. C., Abadía, J., and Abadía, A. (2011). Effects of moderate and severe iron deficiency chlorosis on fruit yield, appearance and composition in pear (Pyrus communis L.) and peach (Prunus persica (L.) Batsch). Environ. Exp. Bot. 71, 280-286.

Andaluz, S., López-Millán, A. F., Peleato, M., Abadía, J., and Abadía, A. (2002). Increases in phospoenolpyruvate carboxylase activity in iron-deficient sugar beet roots: analysis of spatial localization and post-translational modification. Plant Soil 241, 43-48.

Andaluz, S., López-Millán, A. F., Rivas, J., Aro, E., Abadía, J., and Abadía, A. (2006). Proteomic profiles of thylakoid membranes and changes in response to iron deficiency. Photosynth. Res. 89, 141-155.

Bölling, C., and Fiehn, O. (2006). Metabolite profilling of Chlamydomonas reinhardtii under nutrient deprivation. Plant Physiol. 139, 1995-2005.

Brumbarova, T., Matros, A., Mock, H. P., and Bauer, P. (2008). A proteomic study showing differential regulation of stress, redox regulation and peroxidase proteins by iron supply and the transcription factor FER. Plant J. 54, 321-334.

Buhtz, A., Pieritz, J., Springer, F., and Kehr, J. (2010). Phloem small RNAs, nutrient stress responses, and systemic mobility. BMC Plant Biol. 10, 64. doi:10.1186/1471-2229-10-64

Chich, J. F., David, O., Villers, F., Schaeffer, B., Lutomski, D., and Huet, S. (2007). Statistics for proteomics: experimental design and 2-DE differential analysis. J. Chromatogr. B 849, 261-272.

Curie, C., Cassin, G., Couch, D., Divol, F., Higuchi, K., Le Jean, M., Misson, J., Schikora, A., Czernic, P., and Mari, S. (2009). Metal movement within the plant: contribution of nicotianamine and yellow stripe 1-like transporters. Ann. Bot. 103, $1-11$.

De Nisi, P., and Zocchi, G. (2000). Phospoenolpyruvate carboxylase in cucumber (Cucumis sativus L.) roots under iron deficiency: activity and kinetic characterization. J. Exp. Bot. 51, 1903-1909.

DeKock, P., and Morrison, R. (1958). The metabolism of chlorotic leaves. 1. Amino acids. Biochem. J. 70, 266-272.

Donnini, S., Bhakti, P., Negri, A. S., Vigani, G., Espen, L., and Zocchi, G. (2010). Proteomic characterization of iron deficiency response in Cucumis sativus $\mathrm{L}$. roots. BMC Plant Biol. 10, 268. doi:10.1186/1471-2229-10-268

Durrett, T. P., Gassmann, W., and Rogers, E. E. (2007). The FRD3mediated efflux of citrate into the root vasculature is necessary for efficient iron translocation. Plant Physiol. 144, 197-205.

Eide, D., Brodenius, M., Fett, J., and Guerinot, M. (1996). A novel iron-regulated metal transporter from plants identified by functional expression in yeast. Proc. Natl. Acad. Sci. U.S.A. 93, 5624-5628.

Enomoto, Y., Hodoshima, H., Shimada, H., Shoji, K., Yoshihara, T., and Goto, F. (2007). Long-distance signals positively regulate the expression of iron uptake genes in tobacco roots. Planta 227, 81-89.

Fiehn, O. (2003). Metabolic networks of Cucurbita maxima phloem. Phytochemistry 62, 875-886.

Fiehn, O., Wohlgemuth, G., Scholz, M., Kind, T., Lee, D. Y., Lu, Y., Moon, S., and Nikolau, B. (2008). Quality control for plant metabolomics: reporting MSI-compliant studies. Plant J. 53, 691-704.

Forner-Giner, M. A., Llosá, M. J., Carrasco, J. L., Pérez-Amador, M. A., Navarro, L., and Ancillo, G. (2010). Differential gene expression analysis provides new insights into the molecular basis of iron deficiency stress response in the citrus rootstock Poncirus trifoliata (L.) Raf. J. Exp. Bot. 61, 483-490.

Gollhofer, J., Schläwicke, C., Schmidt, W., and Buckhout, T. J. (2011). Members of a small family of nodulin-like genes are regulated under iron deficiency in roots of Arabidopsis thaliana. Plant Physiol. Biochem. 49, 557-564.

Hansen, N., Hopkins, B., Ellsworth, J., and Jolley, V. (2006). "Iron nutrition in field crops," in Iron Nutrition in Plants and Rhizospheric Microorganisms, eds L. L. Barton and J. Abadía (Dordrecht: Springer), 23-59.

Herbik, A., Giritch, A., Horstmann, C. Becker, R., Balzer, H., Baumlein, H., and Stephan, U. (1996). Iron and copper nutrition-dependent changes in protein expression in a tomato wild type and the nicotianamine-free mutant chloronerva. Plant Physiol. 111, 533-540.

Higuchi, K., Saito, A., Mikami, Y., and Miwa, E. (2011). Modulation of macronutrient metabolism in barley leaves under iron-deficient condition. Soil Sci. Plant Nutr. 57, 233-247.

Jeschke, W. D., and Pate, J. S. (1991). Modelling of the partitioning, assimilation and storage of nitrate within root and shoot organs of castor bean (Ricinus communis L.). J. Exp. Bot. 42, 1091-1103.

Jiménez, S., Gogorcena, Y., Hevin, C. Rombolà, A. D., and Ollat, N. (2007). Nitrogen nutrition influences some biochemical responses to iron deficiency in tolerant and sensitive genotypes of Vitis. Plant Soil 290, 343-355.

Laganowsky, A., Gómez, S. M., Whitelegge, J. P., and Nishio, J. N. (2009). Hydroponics on a chip: analysis of the Fe deficient Arabidopsis thylakoid membrane proteome. J. Proteomics 72, 397-415.

Lan, P., Li, W., Wen, T.-N., Shiau, J.-Y., Wu, Y.-C., Lin, W.-D., and Schmidt, W. (2011). iTRAQ protein profile analysis of Arabidopsis roots reveals new aspects critical for Fe homeostasis. Plant Physiol. 155, 821-834.

Larbi, A., Abadía, A., Abadía, J. and Morales, F. (2006). Down coregulation of light absorption, photochemistry, and carboxylation in Fe-deficient plants growing in different environments. Photosynth. Res. 89, 113-126.

Larbi, A., Abadía, A., Morales, F., and Abadía, J. (2004). Fe resupply to Fe-deficient sugar beet plants leads to rapid changes in the violaxanthin cycle and other photosynthetic characteristics without significant de novo chlorophyll synthesis. Photosynth. Res. 79, 59-69.

Larbi, A., Morales, F., Abadía, A., and Abadía, J. (2010). Changes in iron and organic acid concentrations in xylem sap and apoplastic fluid of iron-deficient Beta vulgaris plants in response to iron resupply. J. Plant Physiol. 167, 255-260.

Larbi, A., Morales, F., Abadía, J., and Abadía, A. (2003). Effects of branch solid Fe sulphate implants on xylem sap composition in fieldgrown peach and pear: changes in $\mathrm{Fe}$, organic anions and $\mathrm{pH}$. J. Plant Physiol. 160, 1473-1481.

Li, J., Wu, X., Hao, S., Wang, X., and Ling, H. (2008). Proteomic response to iron deficiency in tomato root. Proteomics 8, 2299-2311.

Li, W., and Schmidt, W. (2010). A lysine63-linked ubiquitin chain-forming conjugase, UBC13, promotes the developmental responses to iron deficiency in Arabidopsis roots. Plant J. 62, 330-343.

López-Millán, A. F., Morales, F., Abadía, A., and Abadía, J. (2001a). Changes induced by $\mathrm{Fe}$ deficiency and $\mathrm{Fe}$ resupply in the organic acid metabolism of sugar beet (Beta vulgaris) leaves. Physiol. Plant. 112, 31-38.

López-Millán, A. F., Morales, F., Abadía, A., and Abadía, J. (2001b). Iron deficiency-associated changes in the composition of the leaf apoplastic fluid from field-grown pear (Pyrus communis L.) trees. J. Exp. Bot. 52, 1489-1498.

López-Millán, A. F., Morales, F., Gogorcena, Y., Abadía, A., and Abadía, J. (2001c). Iron resupply-mediated deactivation of Fe-deficiency stress responses in roots of sugar beet. Aust. J. Plant Physiol. 28, 171-180.

López-Millán, A. F., Morales, F., Andaluz, S., Gogorcena, Y., Abadía, A., De Las Rivas, J., and Abadía, J. (2000a). Responses of sugar beet roots to iron deficiency. Changes in carbon assimilation and oxygen use. Plant Physiol. 124, 885-897.

López-Millán, A. F., Morales, F., Abadía, A., and Abadía, J. (2000b). Effects of iron deficiency on the composition of the leaf apoplastic fluid and xylem sap in sugar beet. Implications for iron and carbon transport. Plant Physiol. 124, 873-884.

López-Millán, A. F., Morales, F., Gogorcena, Y., Abadía, A., and Abadía, J. (2009). Metabolic responses in iron deficient tomato plants. J. Plant Physiol. 166, 375-384.

Marschner, H. (1995). Mineral Nutrition of Higher Plants. London: Academic Press.

Maruyama, T., Higuchi, K., Yoshiba, M., and Tadano, T. (2005). Comparison of iron availability in leaves of barley and rice. Soil Sci. Plant Nutr. 51, 1035-1042.

Mattoo, A. K., Minocha, S. C., Minocha, R., and Handa, A. K. (2010). Polyamines and cellular metabolism in plants: transgenic approaches reveal different responses to diamine putrescine versus higher polyamines spermidine and spermine. Amino Acids 38, 405-413.

Nishio, J. N., and Terry, N. (1983). Iron nutrition-mediated chloroplast development. Plant Physiol. 71, 688-691. 
Ollat, N., Laborde, W., Neveux, M., Diakou-Verdin, P., Renaud, C., and Moing, A. (2003). Organic acid metabolism in roots of various grapevine (Vitis) rootstocks submitted to iron deficiency and bicarbonate nutrition. J. Plant Nutr. 26, 2165-2176.

Orera, I., Rodríguez-Castrillón, J. A., Moldovan, M., García-Alonso, J. I., Abadía, A., Abadía, J., and ÁlvarezFernández, A. (2010). Using a dualstable isotope tracer method to study the uptake, xylem transport and distribution of $\mathrm{Fe}$ and its chelating agent from stereoisomers of an $\mathrm{Fe}$ (III)-chelate used as fertilizer in Fe-deficient strategy I plants. Metallomics 2, 646-657.

Owen, O. E., Kalhan, S. C., and Hanson, R. W. (2002). The key role of anaplerosis and cataplerosis for citric acid cycle function. J. Biol. Chem. 277, 30409-30412.

Rellán-Álvarez, R., Abadía, J., and Álvarez-Fernández, A. (2008). Formation of metal-nicotianamine complexes as affected by $\mathrm{pH}$, ligand exchange with citrate and metal exchange. A study by electrospray ionization time-of-flight mass spectrometry. Rapid Commun. Mass Spectrom. 22, 1553-1562.

Rellán-Álvarez, R., Andaluz, S., Rodríguez-Celma, J., Wohlgemuth, G., Zocchi, G., Álvarez-Fernández, A., Fiehn, O., López-Millán, A. F., and Abadía, J. (2010a). Changes in the proteomic and metabolic profiles of Beta vulgaris root tips in response to iron deficiency and resupply. BMC Plant Biol. 10, 120. doi:10.1186/1471-2229-10-120

Rellán-Álvarez, R., Giner-MartínezSierra, J., Orduna, J., Orera, I., Rodríguez-Castrillón, J. A., GarcíaAlonso, J. I., Abadía, J., and ÁlvarezFernández, A. (2010b). Identification of a tri-iron(III), tri-citrate complex in the xylem sap of irondeficient tomato resupplied with iron: new insights into plant iron long-distance transport. Plant Cell Physiol. 51, 91-102.

Robinson, N., Procter, C., Connolly, E. and Guerinot, M. (1999). A ferricchelate reductase for iron uptake from soils. Nature 397, 694-697.

Rodríguez-Celma, J., Lattanzio, G. Grusak, M. A., Abadía, A., Abadía, J., and López-Millán, A. F. (2011). Root responses of Medicago truncatula plants grown in two different iron deficiency conditions: analysis of the root protein profile and the riboflavin biosynthesis pathway. J. Proteom. Res. 10, 2590-2601.

Rombolà, A. D., and Tagliavini, M. (2006). "Iron nutrition of fruit tree crops," in Iron Nutrition in Plants and Rhizospheric Microorganisms, eds L. L. Barton and J. Abadia (Dordrecht: Springer), 61-83.

Roschzttardtz, H., Séguéla-Arnaud, M., Briat, J. F., Vert, G., and Curie, C. (2011). The FRD3 citrate effluxer promotes iron nutrition between symplastically disconnected tissues throughout Arabidopsis development. Plant Cell 23, 2725-2737.

Santi, S., and Schmidt, W. (2009). Dissecting iron deficiency-induced proton extrusion in Arabidopsis roots. New Phytol. 183, 1072-1084.

Schuler, M., Keller, A., Backes, C., Philippar, K., Lenhof, H. P., and Bauer, P. (2011). Transcriptome analysis by GeneTrail revealed regulation of functional categories in response to alterations of iron homeostasis in Arabidopsis thaliana. BMC Plant Biol. 11, 87. doi:10.1186/1471-2229-11-87

Shakoury-Elizeh, M., Protchenko, O., Berger, A., Cox, J., Gable, K., Dunn, T. M., Prinz, W. A., Bard, M., and Philpott, C. C. (2010). Metabolic response to iron deficiency in Saccharomyces cerevisiae. J. Biol. Chem. 285, 14823-14833.

Sperotto, R. A., Boff, T., Duarte, G. L., and Fett, J. P. (2008). Increased senescence-associated gene expression and lipid peroxidation induced by iron deficiency in rice roots. Plant Cell Rep. 27,183-195.

Sperotto, R. A., Ricachenevsky, F. K., and Fett, J. P. (2007). Iron deficiency in rice shoots: identification of nove induced genes using RDA and possible relation to leaf senescence. Plant Cell Rep. 26, 1399-1411.

Susín, S., Abadía, A., González-Reyes, J. A., Lucena, J. J., and Abadía, J. (1996). The $\mathrm{pH}$ requirement for in vivo activity of the iron deficiency-induced "Turbo"' ferric chelate reductase - a comparison of the iron-deficiency-induced iron reductase activities of intact plants and isolated plasma membrane fractions in sugar beet. Plant Physiol. $110,111-123$

Thimm, O., Essingmann, B., Kloska, S. Altmann, T., and Buckhout, T. J. (2001). Response of Arabidopsis to iron deficiency stress as revealed by microarray analysis. Plant Physiol. 127, 1030-1043.

Thoiron, S., Pascal, N., and Briat, J. F. (1997). Impact of iron deficiency and iron re-supply during the early stages of vegetative development in maize (Zea mays L.). Plant Cell Environ. 20, 1051-1060.

Timperio, A., D'amici, G., Barta, C., Loreto, F., and Zolla, L. (2007). Proteomic, pigment composition, and organization of thylakoid membranes in iron-deficient spinach leaves. J. Exp. Bot. 58, 3695-3710.

von Wirén, N., Klair, S., Bansal, S., Briat, J. F., Khodr, H., Shioiri, T., Leigh, R. A., and Hider, R. A. (1999). Nicotianamine chelates both FeIII and
FeII. Implications for metal transport in plants. Plant Physiol. 119, 1107-1114

Yang, T. J. W., Lin, W. D., and Schmidt, W. (2010). Transcriptional profiling of the Arabidopsis iron deficiency response reveals conserved transition metal homeostasis networks. Plant Physiol. 152, 2130-2141.

Yokosho, K., Yamaji, N., Ueno, D., Mitani, N., and Ma, J. F. (2009). OsFRDL1 is a citrate transporter required for efficient translocation of iron in rice. Plant Physiol. 149, 297-305.

Conflict of Interest Statement: The authors declare that the research was conducted in the absence of any commercial or financial relationships that could be construed as a potential conflict of interest.

Received: 15 July 2011; paper pending published: 27 July 2011; accepted: 04 October 2011; published online: 25 October 2011.

Citation: Rellán-Álvarez $R$, El-Jendoubi $H$, Wohlgemuth $G$, Abadia A, Fiehn O, Abadía J and Álvarez-Fernández A (2011) Metabolite profile changes in xylem sap and leaf extracts of strategy I plants in response to iron deficiency and resupply. Front. Plant Sci. 2:66. doi: 10.3389/fpls.2011.00066

This article was submitted to Frontiers in Plant Nutrition, a specialty of Frontiers in Plant Science.

Copyright (c) 2011 Rellán-Álvarez, ElJendoubi, Wohlgemuth, Abadía, Fiehn, Abadía and Álvarez-Fernández. This is an open-access article subject to a nonexclusive license between the authors and Frontiers Media SA, which permits use, distribution and reproduction in other forums, provided the original authors and source are credited and other Frontiers conditions are complied with. 


\section{APPENDIX}

Table A1 | Main effects of iron deficiency on xylem sap unknown metabolite levels. The corresponding response ratios, defined as the level in the $-\mathrm{Fe}$ treatment divided by the level in the $+\mathrm{Fe}$ treatment, are also shown. When the response ratio was lower than 1, the inverse was taken and the sign changed. Only metabolites showing changes in response ratios larger than 2.0-fold and statistically significant (at $p \geq 0.05$ ) are included in the table.

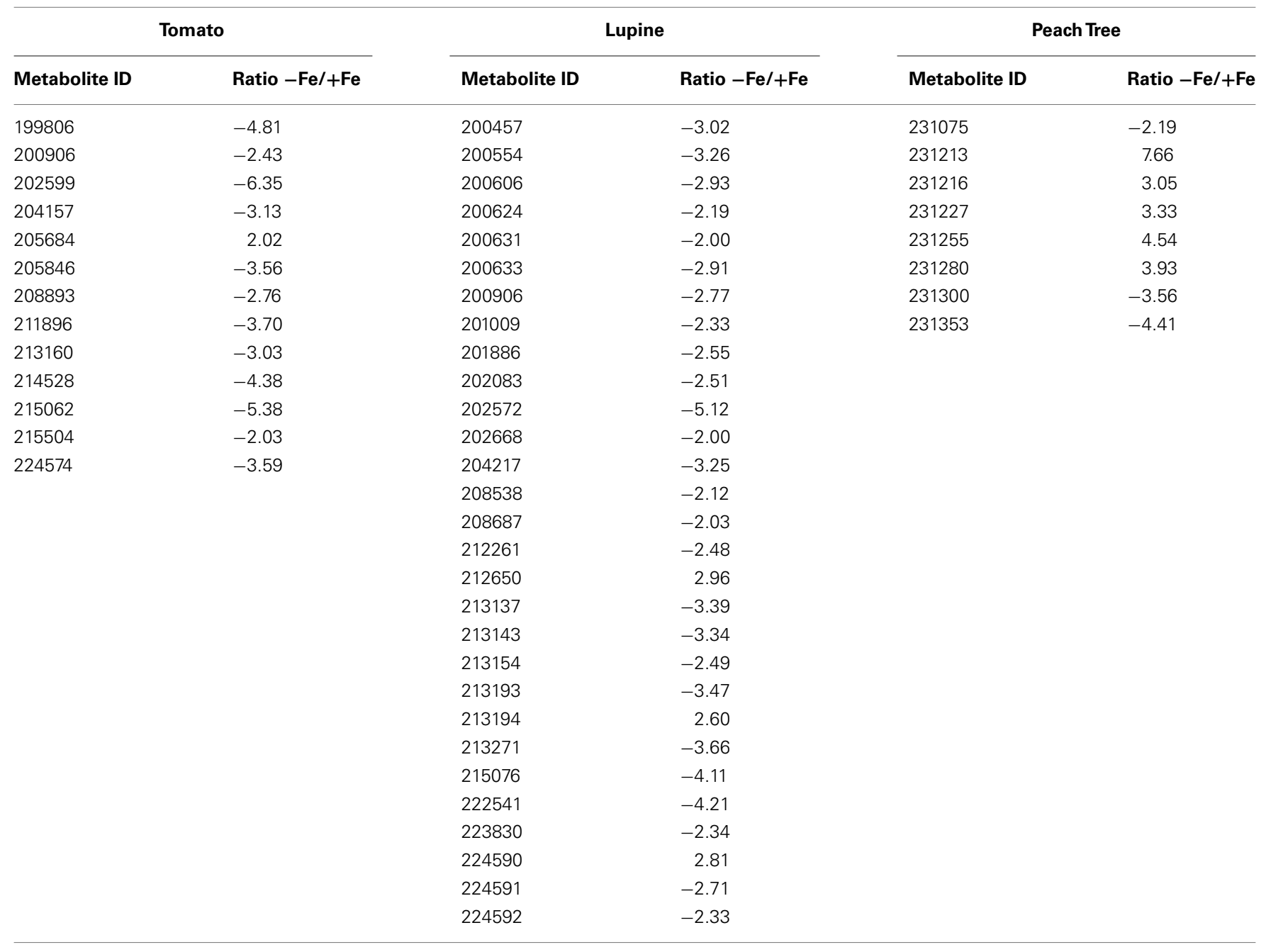


Table A2 | Main effects of iron deficiency on leaf extracts unknown metabolite levels. The corresponding response ratios, defined as the level in the - Fe treatment divided by the level in the +Fe treatment, are also shown. When the response ratio was lower than 1 , the inverse was taken and the sign changed. Only metabolites showing changes in response ratios larger than 2.0-fold and statistically significant (at $p \leq 0.05$ ) are included in the table.

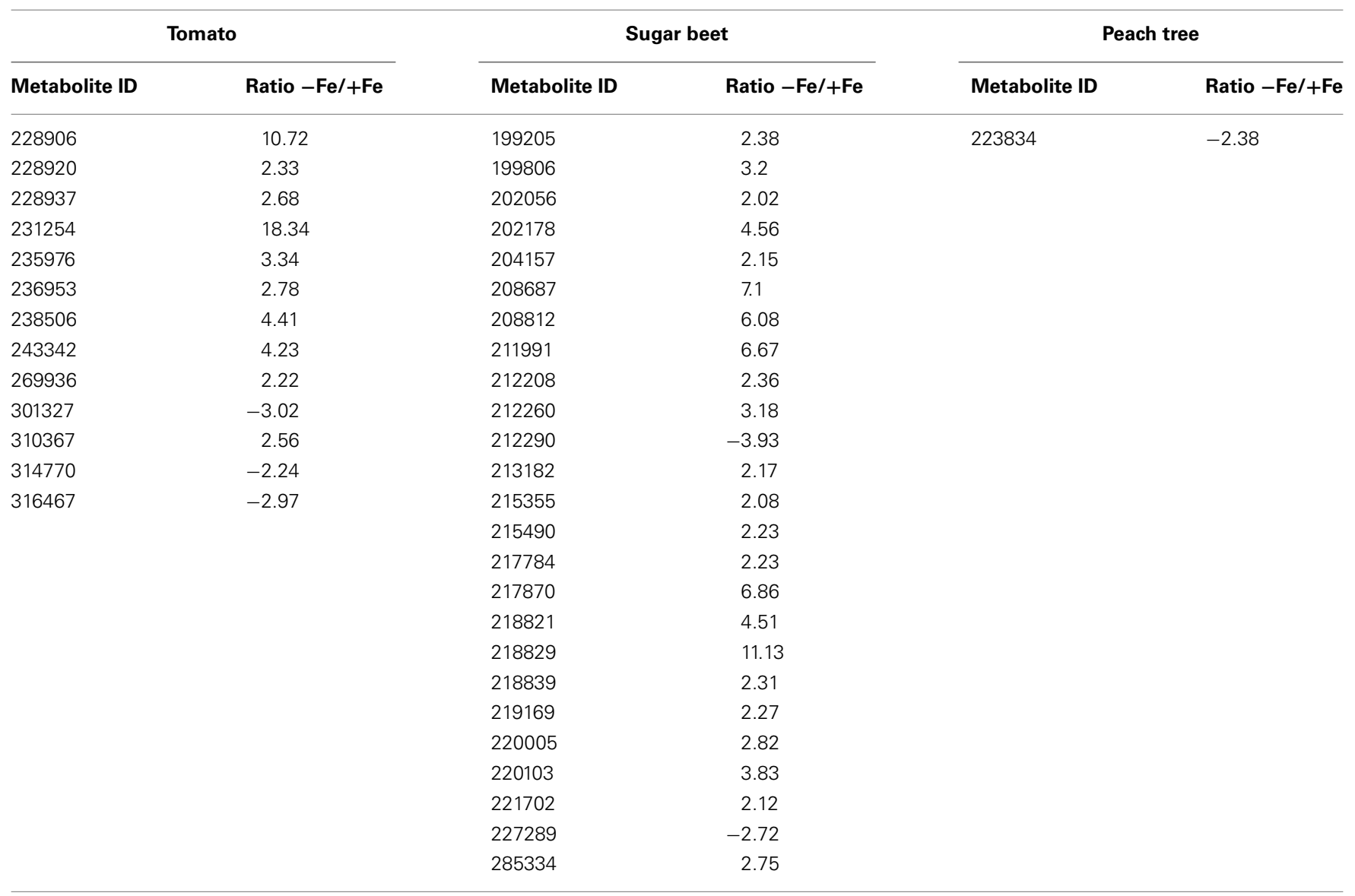

